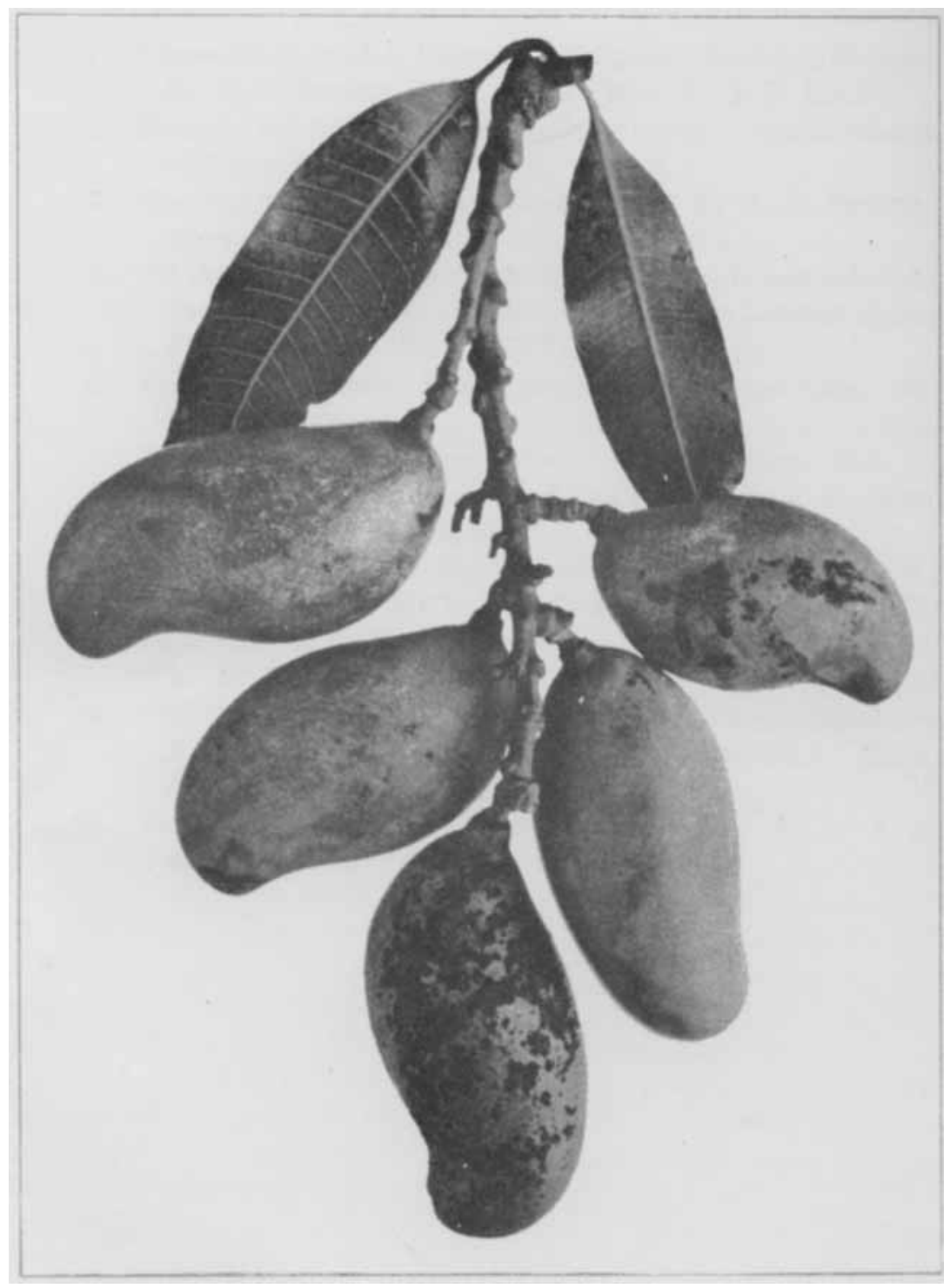

Reproduced, from nature, by the Government Printer, Preforia

Mango fruits, attacked by Bacillus mangiferae 


\title{
A BACTERIAL DISEASE OF THE MANGO. BACILLUS MANGIFERAE N.SP.
}

\author{
By ETHEL M. DOIDGE, M.A., F.L.S., \\ Mycologist, Division of Botany, Pretoria. \\ (Thesis approved for the Degree of Doctor of Science in the \\ University of the Cape of Good Hope.) \\ (With Plates I-XIV and 3 Text-figures.)
}

For some years past, fruit growers in certain districts of this country have been troubled by a disease of mangoes which is causing considerable havoc in their orchards and threatens to seriously affect the export trade.

All parts of the tree are attacked, the affected areas becoming discoloured, while in fruit and stem deep longitudinal cracks also occur; the disease has been described by farmers as resembling in appearance the anthracnose of the grape vine caused by Gloeosporium ampelophagum Sacc., and its external effects are not dissimilar to those caused by that fungus. A large percentage of the fruit falls to the ground whilst yet immature, and the mangoes which remain on the trees are rendered unsightly and unfit for the market.

The disease was first reported in December, 1909, as occurring at Barberton in the Transvaal, and as being unchecked in its progress by repeated applications of Bordeaux mixture. It was soon found that most of the mango-growing districts of the Union were similarly affected and it was considered advisable to make a more detailed study of the disease and the organism causing it, with a viow to formulating, if possible, some method by which its progress might be checked. This purpose has not yet been fully carried out as no effective remedy has been found, but the work has progressed to a point where it seems advisable that the results which have been obtained should be placed on record. 


\begin{abstract}
Literature.
There is no description in available literature of a disease of mangoes in any way resembling the one under discussion. General literature on the mango is very scanty and consists for the most part of pamphlets describing varieties and methods of propagation. In certain of these, however, reference is made to the diseases to which the mango is subject, and a short review of such references may not be out of place here.

Three diseases are reported from Hawaii (7), a blight caused by Colletotrichum sp.; mango scab, and sooty mould. In Hawaii and Cuba the bloom blight due to Gloeosporium mangiferae is common, attacking the opening blossoms and causing them to turn black, dry up and fall ( 3 and 6 ). This disease appears to be common in most districts where the mango is cultivated and has been reported in this country from Natal.
\end{abstract}

There is no reference to any fungous or bacterial trouble in a pamphlet entitled The Mango, its Culture and Varieties, by C. Marshall Woodrow (12), although remedies are suggested against certain insect pests in a paragraph on the "Enemies of the Mango Tree."

"The mango in Porto Rico seems almost entirely free from disease, or the attacks of insects. On the north side of the island the skin of the fruit is frequently disfigured by black spots, probably a fungus. Though in no way injuring the eating quality of the fruit, these detract from its appearance.... In drier localities this discolouration was not observed" (4).

"Some of the varieties of mangoes cultivated in Trinidad are liable to a disease which makes the interior of the fruit assume a dark, jellylike consistency, and the pulp immediately surrounding the seed becomes completely sour and uneatable. This does not arise from being overripe, as the same state of things may be seen in a half-ripe mango if cut. Many of the trees in the Botanic Gardens are affected, and hitherto we have been unable to ascertain the immediate cause."

"It is curious to note, however, that in some cases individual trees only are affected, while others growing near by produce perfectly sound fruit. It is certainly more prevalent with the better class of fruit than with the commoner kinds, but it is to be seen in all more or less. Again, some of the fruit of a tree may be perfectly sound, while another portion just as carefully handled will be utterly useless" (13).

There is no mention of any disease in a paper on "The Mango in South California" (9). 
Of the six diseases mentioned above, four are due to the attacks of fungi; the remaining two, of which the cause has not been determined, differ essentially in their effects from the one to be described.

\section{Geographical distribution.}

Our attention was first drawn to this disease by Messrs Winter Bros. of Barberton, who sent specimens of mangoes from their trees for examination. They stated that it made its first appearance there after the great hail storm in October 1906, which damaged the trees considerably; the marks of the hail are still visible on the trunks and larger branches. A tree standing in a corner of the orchard was the first to become infected, and from this point the infection rapidly spread with the prevailing winds until every tree was diseased. In 1908, in spite of repeated spraying with Bordeaux mixture, they obtained not a single fruit from 60 trees. Almost all the fruit in the town was similarly affected, but at the farms, some distance away, the fruit was then perfectly sound. Every season up to the present (1913-14) the disease has been steadily gaining ground, each year spreading to some orchard which was previously free from infection, and this in spite of the fact that there have been four very dry seasons in succession, a condition which-as will be shown later-is highly unfavourable to the spread of the disease.

In 1910, a sample of infected fruit was received from Warmbaths. On making an inspection of the orchard in which the fruit was grown, it was found that the infection had started at a corner of the orchard where some young trees had been planted. These young trees were badly infected, and, as at Barberton, the infection had spread with the prevailing winds until a large proportion of the trees was affected. The trees which were apparently the original source of infection had been purchased in Natal, and it seemed probable that in this case the disease had been introduced from that province.

The writer visited Natal in March 1910, with a view to discovering whether this was the case, and found that it was prevalent throughout the mango-growing districts of Natal. It was actually observed on the leaves and stems of trees at Hillarys, Malvern and Durban. During a later visit in December 1911 , it was seen on the fruit in all these localities.

In 1910, Mr R. A. Davis, the Government Horticulturist, reported that he had examined trees in Swaziland and found them quite healthy. These trees had all been imported from Natal some 14 years previously, 
and this would seem to point to the fact that the disease was not known in Natal at that time. This idea was confirmed by a statement made by Dr Medley Wood, who was, until recently, Director of the Durban Botanic Gardens, and who informed me that whereas some years back

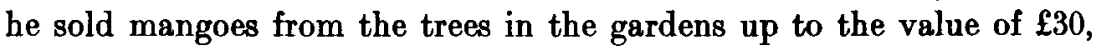
recently he had scarcely obtained sufficient for his own use.

In August, 1911, an inspection of the mango trees at the Tzaneen and Westphalia Estates in the Zoutpansberg District showed them to be quite free from this trouble.

This disease was noted on some mango fruits from Lourenço Marques in November, 1910; but in Portuguese East Africa would appear to be confined to the neighbourhood of Delagoa Bay; for in a letter dated 14th November, 1913, Mr Pole Evans writes: "When I visited Portuguese East Africa in September last, I saw some of the largest mango trees that I have ever seen at Quilimane and Inhambane. The trees were then in flower. I examined carefully for any disease that might be present, and saw no evidence of the bacterial disease. The inhabitants told me that the trees bore well and that the fruit was clean."

In the absence of any reference in available literature to any disease at all resembling the one under discussion, an attempt was made by various means to discover whether it occurred outside South Africa or not.

The symptoms accompanying the disease, which are very characteristic, were described to Dr Erwin F. Smith of Washington, and he stated that he was not aware of the existence of such a disease in America.

With reference to the possible occurrence of this trouble in India, Dr E. J. Butler, Director of the Imperial Agricultural Research Institute, Pusa, in a letter dated the 29th February, 1912, writes as follows:

"Last year for the first time a supposed bacterial disease of mango fruits was reported from the Bengal Agricultural College, Sabour, Bhagalpur. The Indian Assistant Professor of Mycology who examined the disease could find no fungus in the rotted spots on the fruit. Bacteria were naturally present, and he attributed the damage, which was considerable, to this cause. Some fruits were sent to my Laboratory and on examination I found the common Gloeosporium Mangae Noack (probably $G$. Raciborski, common on the leaves) together with a little of a Hendersonia which we have previously found associated with a mango fruit rot. I found no evidence to support the idea that the disease was bacterial." 
At the suggestion of Mr R. A. Davis, we communicated with Mr Cousins, Director of Agriculture in Jamaica, who has devoted considerable time and study both to the cultivation of the mango and to the diseases to which it is subject. Mr Cousins wrote in reply:

"This disease is quite unknown in Jamaica. The mango sometimes suffers from the attack of thrips on the young foliage but otherwise is almost immune from disease and pests in Jamaica."

The majority of the trees in Natal were grown in the first instance from seed imported from Mauritius. Mr Bijoux, the Assistant Director of the Botanic Gardens, Mauritius, was visiting Durban in 'December, 1911. He stated that when he left the island the trees were perfectly healthy and laden with fruit. He knew nothing of the occurrence of such a disease. This information was obtained through the courtesy of Dr Medley Wood.

To summarise: so far as can be ascertained, there is no evidence of the occurrence of this disease outside South Africa. In all the mangogrowing districts of the Union with the exception of the Zoutpansberg, the disease has caused considerable loss. Swaziland is also free from infection. In Portuguese East Africa cases of infection have only been reported from the neighbourhood of Delagoa Bay.

\section{Symptoms of the disease.}

Although the effects of the disease on the fruit are the most conspicuous, and of the greatest importance economically, numerous infections also occur on stems and leaves. The latter do not greatly affect the general health of the tree, but they serve to carry over the infection from one season to the next.

The first signs of infection noticeable on the leaves are a number of small, angular, water-soaked areas bounded by some of the veins of the leaf. These spots do not increase much in size and rarely exceed $2-3 \mathrm{~mm}$. in diameter; but if they are very numerous they coalesce and larger spots are formed. The infected areas soon begin to discolour and become dark brown, the surface is somewhat raised and shining and frequently there is a slight exudation of gum (Plate II). In very old leaves these discoloured spots become white and dry, and crack away. If infection takes place in the petioles-as is often the caselongitudinal cracks result which attain a length of $1 \mathrm{~cm}$. or less.

Diseased spots are also found on all parts of the stem, although it is evident that the majority of the infections take place in young and rapidly growing tissues; they are also common in the scars from which 
leaves have newly fallen. The first appearance of disease in the stem is a discolouration of the tissues. This is accompanied by gummosis and the formation of deep longitudinal cracks. The discolouration is not merely superficial but penetrates some distance into the stem (Plate III).

The disease is especially evident on the peduncles and pedicels; frequently, by the time the fruit is half grown, the whole inflorescence is affected. The stalks to which the mangoes are attached become black and dead, and consequently the fruit all falls to the ground (Plate VI):

As has been mentioned above, although the spots on the leaves and stems are often very numerous, they do not noticeably affect the general health of the tree. Their chief importance is as a source of infection for the fruit which is seriously injured by the disease. Large numbers of mangoes fall to the ground, and the small percentage which remains on the trees is so disfigured as to be practically useless (Plate IV). The mangoes on the windward side of the tree suffer most. The diseased spots first appear on the most exposed side of the fruit or else at the spot where two mangoes on the same bunch are in contact and where a drop of water would lodge after rain. The first sign of infection is a small water-soaked area round the white spot which indicates the presence of a stoma, or near a slight wound; this spreads considerably and then begins to discolour. Cracking takes place in several directions and the surface of the diseased area becomes very much roughened. If infection takes place during a period of rapid growth, deep longitudinal cracks are formed, running almost the whole length of the fruit in bad cases (Plate V).

The discoloured spots vary much in size; they are $1 \mathrm{~mm}$. to $15 \mathrm{~mm}$. in diameter and are irregular in shape, and the discolouration penetrates to a depth of $8-15 \mathrm{~mm}$.

Especially noticeable in the case of infections near the point of attachment of the fruit is the exudation of gum which runs over the surface of the mango. This substance is highly infectious and diseased spots are developed wherever it touches the surface of the fruit.

When a mango has once become diseased the slightest air movement detaches it from the tree, and the ground becomes strewn with decaying fruit. 


\section{Hosts and Varieties affected.}

The disease has been observed on all the varieties of mango commonly grown in this country, but all are not equally susceptible.

The variety known locally as the Peach Mango or Figette is the most resistant. This is a very fine-looking mango and keeps well, but is said to be of inferior flavour.

The most susceptible is the "Baissac" variety, known locally as the "Long Green"; the other three varieties which are commonly grown, namely "Maison Rouge," "Corde" and "Dauphine," are almost as badly affected. These are known locally as the "Long Red," or "Red Kidney," the "Common Yellow" and the "Round Green," respectively.

In view of the fact that so far as is known at present this disease is confined to South Africa, search was made among nearly related indigenous plants for a source of infection. In particular, the "Maroola" tree (Sclerocarya caffra) was examined, as it is very common in districts where the mango is grown. The only specimen of this plant which showed any spots on the leaves proved to be infected with Cercospora sp.; and I have been unable to produce with the bacillus causing the mango disease, any infections on the leaves or fruit of the tree.

\section{Spraying experiments.}

A more detailed study of the progress of the disease was made during the season 1911-1912 in connection with spraying experiments which were being carried out at Barberton in an orchard kindly placed at our disposal by Messrs Winter Brothers. The season was an exceptionally dry one, and consequently unfavourable to the spread of the disease. The following table compiled from statistics furnished by the Meteorological Department shows that the rainfall has been much lower than in the previous seasons. The temperature has been exceptionally high.

Comparative Table. Rainfall 1907-1912.

\begin{tabular}{|c|c|c|c|c|c|c|c|c|c|c|c|c|}
\hline \multirow[b]{2}{*}{ Season } & \multicolumn{2}{|c|}{ September } & \multicolumn{2}{|c|}{ October } & \multicolumn{2}{|c|}{ November } & \multicolumn{2}{|c|}{ December } & \multicolumn{2}{|c|}{ January } & \multicolumn{2}{|c|}{ Total } \\
\hline & $\begin{array}{l}\text { No. of } \\
\text { ins. }\end{array}$ & $\begin{array}{c}\text { No. of } \\
\text { days }\end{array}$ & $\begin{array}{l}\text { No. of } \\
\text { ins. }\end{array}$ & $\begin{array}{c}\text { No. of } \\
\text { days }\end{array}$ & $\begin{array}{l}\text { No. of } \\
\text { ins. }\end{array}$ & $\begin{array}{c}\text { No. of } \\
\text { days }\end{array}$ & $\begin{array}{l}\text { No. of } \\
\text { ins. }\end{array}$ & $\begin{array}{l}\text { No. of } \\
\text { days }\end{array}$ & $\begin{array}{l}\text { No. of } \\
\text { ins. }\end{array}$ & $\begin{array}{l}\text { No. of } \\
\text { days }\end{array}$ & $\begin{array}{l}\text { No. of } \\
\text { ins. }\end{array}$ & $\begin{array}{l}\text { No. of } \\
\text { days }\end{array}$ \\
\hline $1007-8$ & $\cdot 14$ & 2 & $2 \cdot 18$ & 9 & $4 \cdot 14$ & 15 & $4 \cdot 15$ & 10 & $3 \cdot 62$ & 9 & $14 \cdot 59$ & 45 \\
\hline $1908-9$ & $2 \cdot 38$ & 3 & $2 \cdot 42$ & 12 & $3 \cdot 76$ & 12 & $3 \cdot 78$ & 8 & $14 \cdot 99$ & 17 & $27 \cdot 33$ & 52 \\
\hline $1009-10$ & $\cdot 63$ & 4 & $1 \cdot 78$ & 7 & $3 \cdot 70$ & 13 & $6 \cdot 74$ & 12 & $5 \cdot 51$ & 15 & $18 \cdot 36$ & 51 \\
\hline $1810-11$ & $1 \cdot 14$ & 5 & $4 \cdot 13$ & 14 & $3 \cdot 88$ & 13 & $5 \cdot 41$ & 13 & $7 \cdot 95$ & 10 & $22 \cdot 51$ & 55 \\
\hline $1911-12$ & 07 & 1 & $4 \cdot 63$ & 13 & $2 \cdot 35$ & 10 & $2 \cdot 61$ & 12 & $I \cdot 74$ & 9 & $11 \cdot 40$ & 45 \\
\hline
\end{tabular}


The orchard in which the spraying experiments were carried out is situated on a slope to the east of the town, and contains 28 trees arranged in four rows of seven trees each. The trees are ten or twelve years old and comparatively small-about 12 feet high and 35 feet in circumference-so that the spraying could be thoroughly done.

There is a range of hills to the south of the orchard and the prevailing winds are from the south-east. The disease had started in the south-east corner of the orchard, and from there had spread right through. Before the experiments were commenced the trees were all diseased: row (1) being bad right through while in the other rows trees (6) and (7) were the worst.

\section{Plan of Winter Bros. Orchard, Barberton.}

\begin{tabular}{|c|c|c|c|c|c|c|c|c|}
\hline & & & & & $200 f$ & & & \\
\hline & (1) & (2) & (3) & (4) & (5) & (6) & (7) & Row 1. \\
\hline North & (1) & (2) & (3) & (4) & (6) & (6) & (7) & Row 2. \\
\hline $150 \mathrm{ft}$. & (1) & (2) & (3) & (4) & (5) & (6) & (7) & Row 3. \\
\hline & (1) & (2) & (3) & (4) & (5) & (6) & (7) & Row \\
\hline
\end{tabular}

Four Rows of Mango Trees, 18 feet apart.

The arrow indicates the direction of the prevailing winds.

* These trees were the first to contract the disease.

Rows 1 and 3 were sprayed with an iron sulphide solution, using the following formula:

$\begin{array}{lllc}\text { Quicklime } & \ldots & \ldots & 4 \text { lbs. } \\ \text { Flowers of sulphur } & \ldots & 4, " \\ \text { Iron sulphate } & \ldots & \ldots & 1 \frac{1}{2}, \\ \text { Water } & \ldots & \ldots & 25 \text { gallons }\end{array}$

and following the directions given in the circular published by this Division.

Rows 2 and 4 were sprayed with Bordeaux mixture, using a 2-2-50 formula for the first spraying and a 4-4-50 in subsequent applications.

In each row tree No. (3) was left unsprayed as a control.

The experiment was carried out by $\mathrm{Mr}$ P. A. van der Bijl, M.A., of this Division, and he was assisted in the earlier part of the work by Mr H. F. Benger. During the seasons 1912-1913 and 1913--1914, the spraying was also done by $\mathrm{Mr}$ van der $\mathrm{Bijl}$, and it is from his reports that this account of the spraying experiments is compiled.

The following table gives the result of the experiment in connection with weather conditions, etc. The slight discrepancy between this and 
the previous table is due to the fact that the first gives the rainfall in the whole district, the second in Barberton only.

Season 1911-12.

\begin{tabular}{|c|c|c|c|c|c|c|c|}
\hline $\begin{array}{c}\text { Week } \\
\text { ending }\end{array}$ & Rainfall & $\begin{array}{l}\text { Tempe } \\
\text { Max. }\end{array}$ & $\begin{array}{l}\text { rature } \\
\text { Min. }\end{array}$ & $\begin{array}{c}\text { Remarks on } \\
\text { Weather }\end{array}$ & Treatment & $\begin{array}{c}\text { Development } \\
\text { of Fruit }\end{array}$ & $\begin{array}{c}\text { Progress } \\
\text { of } \\
\text { Disease }\end{array}$ \\
\hline 26. 8. 11 & None & & & $\begin{array}{l}\text { No rain up } \\
\text { to } 30.9 .11\end{array}$ & $\begin{array}{c}\text { lst } \\
\text { spraying }\end{array}$ & $\begin{array}{l}\text { Trees in } \\
\text { flower }\end{array}$ & $\begin{array}{l}\text { Old leaves } \\
\text { badly } \\
\text { diseased }\end{array}$ \\
\hline 7. 10.11 & $2.66 \mathrm{in}$. & $74^{\circ} \mathrm{E}$ & $52^{\circ} \mathrm{F}$ & $\begin{array}{c}\text { First heavy } \\
\text { rain of } \\
\text { season }\end{array}$ & & & \\
\hline 14.10 .11 & None & & & & & & \\
\hline 21. 10.11 & $01 \mathrm{in.}$ & & & & $\begin{array}{l}\text { 2nd } \\
\text { spraying }\end{array}$ & $\begin{array}{c}\text { Fruit about } \\
\text { the size of } \\
\text { walnuts }\end{array}$ & $\begin{array}{l}\text { No sign of } \\
\text { disease on } \\
\text { fruit }\end{array}$ \\
\hline 28. 10. 11 & $61 \mathrm{in.}$ & $70^{\circ} \mathrm{F}$. & $58^{\circ} \mathrm{F}$. & $\begin{array}{c}\text { Three weeks } \\
\text { since lst } \\
\text { rain }\end{array}$ & & $\begin{array}{l}\text { Fruit } 1 \frac{1}{2}^{\prime \prime} \\
\text { to } 2^{n} \text { long }\end{array}$ & $\begin{array}{c}\text { Diseased } \\
\text { spots first } \\
\text { noticed on } \\
\text { fruit }\end{array}$ \\
\hline 4. 11.12 & $.87 \mathrm{in}$. & $74^{\circ} \mathrm{F}$. & $52^{\circ} \mathrm{F}$. & & & & \\
\hline 11. 11.11 & $.08 \mathrm{in}$. & $78^{\circ} \mathrm{F}$ & $54^{\circ} \mathrm{F}$ & & $\begin{array}{l}\text { 3rd } \\
\text { spraying }\end{array}$ & & $\begin{array}{c}\text { A bout } 5 \% \\
\text { of fruit } \\
\text { diseased }\end{array}$ \\
\hline 18. 11.11 & 46 in. & $86^{\circ} \mathrm{F}$. & $54^{\circ} \mathrm{F}$. & & & & \\
\hline 25. 11. 11 & $1 \cdot 29$ in. & & & & & & \\
\hline 2. 12.11 & 2.06 in. & $82^{\circ} \mathrm{F}$. & $64^{\circ} \mathrm{F}$. & & $\begin{array}{l}\text { 4th } \\
\text { spraying }\end{array}$ & $\begin{array}{l}\text { Fruit 3-4 } \\
\text { ins. long }\end{array}$ & $\begin{array}{c}\text { Disease } \\
\text { spreading. } \\
\text { About } 7 \% \\
\text { disease }\end{array}$ \\
\hline 9.12 .11 & $.58 \mathrm{in}$. & & & & & & \\
\hline 16.12 .11 & 45 in. & & & & & & \\
\hline 23. 12.11 & $6 \mathrm{in}$ & $98^{\circ} \mathrm{F}$. & $64^{\circ} \mathrm{F}$ & & & & \\
\hline 30.12 .11 & 5 in. & $90^{\circ} \mathrm{F}$ & $58^{\circ} \mathrm{F}$. & & & & \\
\hline 6. 1.12 & $86 \mathrm{in.}$ & $100^{\circ} \mathrm{F}$ & $62^{\circ} \mathrm{F}$. & & & & \\
\hline 13. 1.12 & & $88^{\circ} \mathrm{F}$. & $54^{\circ} \mathrm{F}$ & & & & \\
\hline 20. 1.12 & $11 \mathrm{in.}$ & $92^{\circ} \mathrm{F}$ & $62^{\circ} \mathrm{F}$ & & & $\begin{array}{l}\text { Almost full } \\
\text { grown }\end{array}$ & $\begin{array}{l}\text { Fruit on } \\
\text { all trees } \\
\text { diseased } \\
40-70 \% \\
\text { affected }\end{array}$ \\
\hline
\end{tabular}

Diseased spots were first observed on the fruit about three weeks after the first rain of the season.

The final estimate of the percentage of diseased fruit refers only to the mangoes still on the trees; large numbers had fallen to the ground and rotted.

The result of the experiment was far from encouraging. On the 20th January an estimate of the number of mangoes still on the trees showed $30.7 \%$ free from disease on the trees sprayed with iron sulphide 
solution; $54 \%$ on those sprayed with Bordeaux mixture and $67 \%$ on the control trees.

A second spraying experiment was carried out during the season 1912-13, but unfortunately weather conditions were again unfavourable.

The spraying was done in the orchard described above, trees Nos. 3 , 5 and 7 in each row being left as controls and the remainder being sprayed with Hycol in the proportion of half a pint to 40 gallons of water ( 1 in 600 ). The trees were sprayed four times, and at the time for the first and second sprayings the ground was disinfected with Hycol in the proportion of half a pint of $\mathrm{Hycol}$ to 20 gallons of water ( 1 in 300 ).

The season was an exceptionally dry one, the fruit developing slowly, and some trees failing to set any fruit at all.

Owing to the drought, the disease spread very slowly early in the season; the first infections on the fruit being observed early in December. The trees were sprayed for the fourth time on the 4th December and on this occasion it was computed that $45 \%$ of the fruit on the sprayed trees was infected and $1.2 \%$ of that on the unsprayed.

In January the experiment was discontinued owing to the fact that the fruit had been severely cut up by a hailstorm on the 20th of December. On the 7 th of January it was calculated that the unsprayed trees had dropped $36.1 \%$ of their fruit and the sprayed trees $38.8 \%$ since the previous examination. Of the fruit which remained on the tree there was $16.7 \%$ of the fruit on the unsprayed trees diseased as compared with $7 \cdot 3 \%$ on the sprayed trees. The latter seemed to have made more growth than the former, and the Hycol had not damaged the fruit or foliage in any way. The trees which were sprayed with iron sulphide solution during the previous season had received a severe check.

The results of this experiment as far as they went were more encouraging than those of the previous one, but owing to their having been brought to such a premature end they were not sufficiently conclusive, and a further test was necessary. A table is appended showing the rainfall, temperature, etc., during the season.

The spraying with Hycol was continued during the season 1913-14. The first spraying was done on the 29th August, when the trees and the soil underneath them were thoroughly drenched with Hycol 1.600. The trees were then in flower. 
Season 1912-13.

\begin{tabular}{|c|c|c|c|c|c|c|c|}
\hline $\begin{array}{l}\text { Week } \\
\text { ending }\end{array}$ & Rainfall & $\begin{array}{l}\text { Tempe } \\
\text { Max. }\end{array}$ & $\begin{array}{c}\text { rature } \\
\text { Min. }\end{array}$ & $\begin{array}{c}\text { Remarks on } \\
\text { Weather }\end{array}$ & Treatment & $\begin{array}{l}\text { Development } \\
\text { of Fruit }\end{array}$ & $\begin{array}{c}\text { Progress } \\
\text { of } \\
\text { Disease }\end{array}$ \\
\hline 11. 9.12 & Nil. & - & - & $\begin{array}{l}\text { Sun and } \\
\text { wind }\end{array}$ & $\begin{array}{c}\text { Sprayed } \\
\text { with Hycol }\end{array}$ & Blossoming & \\
\hline 18. 9.12 & ", & - & - & Hot sun & & $\begin{array}{l}\text { Blossoms } \\
\text { and fruit } \\
\text { developing } \\
\text { slowly on } \\
\text { sccount of } \\
\text { drought }\end{array}$ & \\
\hline 25. 9.12 & , & - & - & $\begin{array}{l}\text { Sun and } \\
\text { wind }\end{array}$ & & & \\
\hline 2. 10.12 & ", & $8^{\circ} \mathrm{F}$. & $45^{\circ} \mathrm{F}$. & $\begin{array}{l}\text { Sun and } \\
\text { cloud }\end{array}$ & $\begin{array}{c}\text { Sprayed } \\
\text { with Hycol }\end{array}$ & & \\
\hline 9. 10.12 & ", & $92^{\circ} \mathrm{F}$. & $45^{\circ} \mathrm{F}$ & $\begin{array}{l}\text { Sun and } \\
\text { cloud }\end{array}$ & & & $\underset{\text { infections }}{\text { No new }}$ \\
\hline 16. 10.12 & " & $99^{\circ} \mathrm{F}$. & $50^{\circ} \mathrm{F}$. & Sun & & $\begin{array}{l}\text { Very back- } \\
\text { ward through } \\
\text { drought }\end{array}$ & $\begin{array}{c}\text { yet } \\
\text { evident }\end{array}$ \\
\hline 23.10 .12 & Drops & $107^{\circ} \mathrm{F}$ & $60^{\circ} \mathrm{F}$ & $\begin{array}{l}\text { Sun and } \\
\text { cloud }\end{array}$ & & & \\
\hline 30. 10.12 & $.49 \mathrm{in}$. & $90^{\circ} \mathrm{F}$. & $62^{\circ} \mathrm{F}$. & $\begin{array}{l}\text { Sun and } \\
\text { showers }\end{array}$ & $\begin{array}{c}\text { Sprayed } \\
\text { with Hycol }\end{array}$ & & \\
\hline 6. 11. 12 & Nil. & $106^{\circ} \mathrm{F}$. & $62^{\circ} \mathrm{F}$ & Sun & & & \\
\hline 13. 11.12 & " & $108^{\circ} \mathrm{F}$. & $59^{\circ} \mathbf{F}$ & $\begin{array}{l}\text { Sun and } \\
\text { cloud }\end{array}$ & & $\begin{array}{c}\text { Fruit } \\
\text { small } \\
\text { through } \\
\text { drought }\end{array}$ & \\
\hline 20. 11.12 & $2 \cdot 18 \mathrm{in.}$ & $97^{\circ} \mathrm{F}$. & $48^{\circ} \mathrm{F}$ & $\underset{\text { rain }}{\text { Sun and }}$ & & & \\
\hline $\begin{array}{r}\text { 27. } 11.12 \\
\text { 4. } 12.12\end{array}$ & $\begin{array}{l}\text { Nil. } \\
.05 \text { in. }\end{array}$ & $\begin{array}{l}110^{\circ} \mathrm{F} \text {. } \\
103^{\circ} \mathrm{F}\end{array}$ & $\begin{array}{l}55^{\circ} \mathrm{F} \\
66^{\circ} \mathrm{F} .\end{array}$ & $\begin{array}{l}\text { Sun } \\
\text { Sun and } \\
\text { eloud }\end{array}$ & $\begin{array}{c}\text { Sprayed } \\
\text { with Hycol }\end{array}$ & & $\begin{array}{c}\text { Disease } \\
\text { now } \\
\text { spreading } \\
\text { rapidly }\end{array}$ \\
\hline 11. 12.12 & 2.51 in. & $105^{\circ} \mathrm{F}$. & $65^{\circ} \mathrm{F}$. & $\begin{array}{l}\text { Sun and } \\
\text { storm }\end{array}$ & & $\begin{array}{c}\text { Much } \\
\text { damaged } \\
\text { by hail }\end{array}$ & $\begin{array}{c}\text { Disease } \\
\text { now } \\
\text { spreading } \\
\text { fast }\end{array}$ \\
\hline
\end{tabular}

18. $12.12 \quad 3$ in. $\quad 95^{\circ}$ F. $62^{\circ}$ F. Sun and

25. $12.12 \quad 1.5$ in. $\quad 96^{\circ} \mathrm{F}$. $67^{\circ} \mathrm{F}$. Sun and

Expori- Nearly all

heavy hail ment dis- fruit cut

and the

remainder

bearing

hail marks

The second spraying was done with Hycol $1: 300$ on the 6th October, after the fruit had set and was $2-3 \mathrm{~cm}$. in length. On the third application of the spray on the 15th of November, the fruit had attained a length of $4-5 \mathrm{~cm}$. and the disease had begun to appear both on the sprayed trees and the controls. 
On the 26th January, Mr van der Bijl paid his final visit to Barberton in connection with the spraying experiments. The fruit on both sprayed trees and controls had nearly all fallen, and most of those which remained were diseased. It is therefore evident that $\mathrm{Hycol}$ is useless in preventing the spread of the disease.

This was again a dry season. About $2 \frac{1}{2}$ inches rain fell between the first and second sprayings, and about 2 inches accompanied by hail between the second and third. The fruit was slightly injured by the hailstones.

Mr Winter reported that the disease has this season spread through the valley, and that he has noticed diseased fruit on his farm at some distance from the village.

From the account of spraying experiments given above, it is evident that the sprays used up to the present are useless in combating this disease; and that iron sulphide is worse than useless as it injures the foliage and thus promotes the spread of infection. The mango being an evergreen tree it is impossible to check the disease by pruning as in the case of "fire blight" and other diseases of deciduous trees.

The risk of infection can be slightly reduced by gathering and burning all diseased fruit and leaves and by keeping the soil under trees damp with some germicide which will prevent the dust from blowing about in the wind and carrying with it the infective bacteria; but no remedial measures used up to the present can be recommended as being really effectual.

\section{The cause of the disease.}

A large number of diseased plants have been examined, and in every case the tissues of the discoloured areas in the leaves, stem and fruit were crowded with bacteria.

An organism was isolated from a diseased fruit from Barberton in November, 1909 ; as it occurred in the host it was a short rod with rounded ends about $1.5 \times \cdot 6 \mu$. A pure culture was obtained without any difficulty. The same organism has since been isolated dozens of times from fruit and leaves of trees growing in Warmbaths, Barberton and several localities in Natal ; in every instance an almost pure culture was obtained at once, except in the case of very old infections on the fruit where a number of yeasts and bacilli have established themselves.

The method used in isolating the organism was as follows: A fairly young infection on the fruit was selected, the surface seared with a hot knife, then a portion of the underlying tissues was cut out with a hot 
sterile knife and dropped into a tube of sterile distilled water; from this a series of plates was poured.

A different method was adopted with the leaves because the organism diffuses very slowly into water from the leaf tissues. A leaf was washed in 1:1000 mercuric chloride, then in several lots of distilled water. A glass pestle and mortar similarly treated, and then an infected part of the leaf ground up in it with some sterile sand and a little distilled water. A drop of the liquid was put into a tube of medium and plates poured.

After the organism had been repeatedly isolated in the way described above, attempts were made to infect a number of young mango trees. The inoculation work has been rendered difficult by the entire absence of any greenhouse accommodation. The trees do not thrive in the open in Pretoria and though they have flowered for two seasons they have not developed any fruit.

It has already been shown that the majority of the natural infections take place in vigorously growing tissues during a spell of wet weather. There have been three very dry seasons since the inoculation work was commenced (1911-12), and it is almost impossible to obtain infections in the open in dry weather.

The few successful inoculations described below, were obtained during a short spell of rain and cloud. There have been a proportionally large number of failures, but in no case have any of the control plants become infected.

This phase of the work will be continued as soon as suitable greenhouse accommodation is available.

\section{Direct infection experiments.}

1. A small portion of the gummy substance exuding from an infected spot on a mango fruit was inoculated by needle pricks into the stem and petioles of a young mango tree. After about four weeks there were discoloured areas round the needle pricks, later longitudinal cracks were formed. The following season these stem and petiole infections were responsible for a number of spots in the leaves in their immediate vicinity. The controls remained healthy.

Cultures of the organism were obtained from the discoloured areas, whose tissues were crammed with bacteria.

2. Portions of diseased tissue were crushed, and the bacteria allowed to diffuse in sterile distilled water. Part of the liquid containing the bacteria was then allowed to stream over both surfaces of 
three leaves of a young mango tree. Each leaf was covered for 24 hours with a large glass tube plugged with cotton wool. Characteristic dark angular spots appeared on the inoculated leaves at the end of four weeks.

There were no spots on the controls.

3. Leaves on a third tree were infected successfully in a similar way to that described in experiment No. 2, with the exception that the bacteria were allowed to diffuse in sterile beef bouillon instead of in distilled water.

The controls remained clean.

Inoculation with pure cultures.

4. A young agar streak culture was suspended in sterile distilled water, and the water was allowed to stream over both sides of two leaves of a young mango tree which were covered over for 24 hours as described in experiment 2. A period of cloudy and rainy weather succeeded the date of this inoculation and of those previously described.

Infections were visible on the 21st day, in the form of small, angular, water-soaked looking areas. After a few days these areas began to change colour and rapidly became black. The discoloured tissues were crowded with bacteria, and a pure culture of the specific organism was at once obtained.

There was no sign of infection on the controls.

5. A second experiment was conducted similar to the above, but small punctures were made in the leaf surface with a fine needle. In this case a large proportion of the infections occurred in the neighbourhood of the needle pricks.

Controls pricked with a sterile needle showed no sign of infection.

6. A set of detached mango fruits was washed in 1:1000 merouric chloride, and then in distilled water. They were sprayed with a suspension of a pure culture of the organism and then covered over with a bell jar. After about three weeks there was a small discoloured area round some of the stomata; the blackened areas containing numbers of bacteria. The observation could not be carried further as the fruit was destroyed by Gloeosporium sp. No blackening was seen in the controls. Other attempts to infect detached leaves and fruit all resulted in failure, as, in spite of all precautions, they were always attacked by Gloeosporium sp. before any infections could show themselves.

7. During the season 1912-13 no inoculations were attempted, but the work was resumed in the spring of 1913 . The weather was again 
very hot and dry. A young culture was used, a number of young leaves being inoculated on the 13th October by means of needle pricks, and the tree covered over with a wet tent for 24 hours after inoculation. This resulted in a number of small infections chiefly in the region of the needle pricks.

8. A second young tree was inoculated on the 3rd of November. There were a number of very young leaves on the tree, which had not yet lost their red colour; in some of these minute punctures were made with a fine needle and the whole was sprayed with the suspension of a young culture in distilled water. The tree was covered with wet sacks for 48 hours after inoculation. After $27-28$ days, there were a few infections on all the younger leaves of the tree, especially in the neighbourhood of the needle pricks and a pure culture of the specific organism was readily obtained from the infected areas. disease.

In both the above experiments the controls were entirely free from

9. Attempts were made in the season $1911-12$ to infect some fruits of the "Maroola tree" (Sclerocarya caffra) but without success.

\section{Natural methods of infection.}

It has been noticed in every instance up to the present that the spread of infection is in the direction of the prevailing winds. It seems probable, therefore, that the wind is the principal agent in spreading the disease and that the organism is carried to a large extent with the dust from beneath the trees. It has been noticed that where the ground is kept free of decaying vegetation and soaked with some germicide, that the spread of infection is to some extent arrested. It has also been chis rved that when the trees are growing among long grass the infection does not spread nearly so rapidly as when the ground under the trees is bare. This supports the supposition that the infective bacteria are largely carried by the wind.

The younger leaves and the fruit are undoubtedly infected by the rain dripping from diseased leaves. An infected spot is almost invariably found where two fruits are in contact and where a drop of water can easily lodge.

I have noticed very few insects on the trees; they do not appear to feed to any great extent on the mango foliage, and one rarely sees any leaves disfigured by insects. The common stink-bug (Anoplocnemis curvipes) is sometimes found on the young foliage, but is probably not responsible to any great extent for spreading the disease. 


\section{Morbid anatomy.}

Some difficulty was experienced in obtaining good sections, as the tissues, especially of the leaves, are very tough and are apt to tear out of the paraffin. The best results were obtained after fixing in acetic alcohol, which was used hot; and embedding in paraffin in M.P. $60^{\circ} \mathrm{C}$. The stain which gave the best result was a combination of Ziehl's carbol fuchsin with light green.

The organism causes no hyperplasias and appears to be entirely confined to the parenchyma. It makes its way into the tissues through a slight abrasion of the surface; it seems very probable that it can also gain an entrance through the stomata, but I have not yet been able to obtain sections which would establish the fact. When once it has effected an entrance, the organism multiplies rapidly and invades the surrounding tissues (Plate VII). The bacteria are very plentiful in the intercellular spaces, and appear to wedge apart the cells and dissolve the middle lamella (Plate IX); one frequently notices in sections through the fruit, a cell which is apparently still untouched, but is completely isolated and surrounded by masses of bacteria.

In some cases the bacteria appear to be intracellular also, but it is almost impossible to judge whether this is really the case or whether the rods have been dragged over the surface of the cells in sectioning; probably the latter.

A good deal of gummosis takes place during the destruction of these cells, the walls of which become swollen and discoloured. The discolouration does not appear to be due to any staining caused by the bacteria but to the decomposition of the cells which are attacked.

The swelling of the disorganised cells is so marked that even in the leaf the surface of the affected area appears raised to the naked eye. The increased thickness of the diseased region is well shown in the section photographed in Plate $X$. In the fruit this is even more marked and so also is the exudation of gum from the diseased tissues.

The nuclei of the cells in the affected area are abnormally large, and stain deeply with the fuchsin; they are very conspicuous in sections through young infections on the fruit.

As the tissues become disintegrated and the cells killed, the bacteria disappear from the dead areas and are found in more deep-seated tissues (Plate VIII). They do not appear to be capable of attacking lignified tissues-in a number of sections examined there was no trace of bacteria in the fibro-vascular bundles of fruit or leaf, although the 
surrounding spaces were crowded with bacteria, numbers of which were lying in close contact with the lignified walls.

In the section represented in Plate VIII a number of yeasts were visible in the broken down cells of the surface tissues, but were not present in very great numbers.

For this reason, the infections in the stem very soon cease to increase in size, and can only take place near the growing tip. The diseased spots in the leaf are bounded by some of the smaller veins.

\section{Morphology of the organism. Dimensions.}

The organism is a short rod with rounded ends, varying considerably in size on different media.

In the host plant it measures from $\cdot 8 \mu$ to $2 \cdot 6 \mu$, by $\cdot 5 \mu$ to $\cdot 7 \mu$. The majority are 1.5 to $1.8 \mu$ by $\cdot 6 \mu$.

In a preparation made from a 24 hours old culture on nutrient agar ( -15 Fuller) and stained with aqueous Gentian Violet, the limits of length were $\cdot 9 \mu$ and $2.7 \mu$; the breadth varied from .5 to $\cdot 7 \mu$. The average was $1 \cdot 5 \mu \times \cdot 6 \mu$. The following are some actual measurements:

$\begin{array}{rc}1 \cdot 5 \mu \times \cdot 6 \mu & 2 \cdot 4 \mu \times \cdot 7 \mu \\ 1 \cdot 6 \mu \times 6 \mu & 1 \cdot 6 \mu \times \cdot 6 \mu \\ 2 \cdot 24 \mu \times \cdot 6 \mu^{*} & 2 \cdot 3 \mu \times \cdot 6 \mu^{*} \\ 1 \cdot 4 \mu \times \cdot 5 \mu & 2 \cdot 7 \mu \times \cdot 6 \mu^{*} \\ 1.4 \mu \times \cdot 6 \mu & \cdot 9 \mu \times \cdot 6 \mu\end{array}$

The rods marked * were just about to divide, and the last in the list was the result of a recent division.

In beef broth cultures 21--24 hours old, short rather thick forms predominate; the rods measure $\cdot 9$ to $1.4 \mu \times \cdot 6$ to $\cdot 8 \mu$. The following are some actual measurements taken from a preparation stained with carbol fuchsin:

$$
\begin{array}{r}
2.1 \mu \times .8 \mu \\
.9 \mu \times .8 \mu \\
.9 \mu \times .7 \mu
\end{array}
$$

In gelatine cultures the rods are exceptionally small, the majority measuring $\cdot 9$ to $1 \mu$ by $\cdot 5$ to $\cdot 6 \mu$. In slides made from a gelatine plate culture three days' old, the longest observed were only $1 \cdot 6 \mu$.

In solutions containing large percentages of sodium chloride, e.g., beef broth containing 7 to $8.75 \% \mathrm{NaCl}$ the organism grows out into long threads which are very variable in length and thickness (Plate XIII, fig. a). They are not septate, and a drop from a beef broth culture containing $7 \% \mathrm{NaCl}$ examined with the paraboloid condenser showed 
several of these long filaments in fairly active motion. Some of the longest ones are swollen irregularly and might perhaps be classed as 'involution forms.' They are again mentioned later under this heading.

The following are some measurements of such filaments from a preparation made from a three days' old nutrient broth culture containing $8.5 \% \mathrm{NaCl}$.

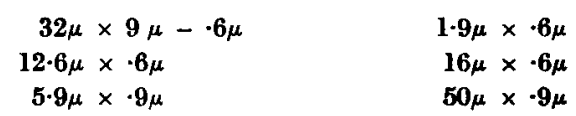

In cultures containing $7 \% \mathrm{NaCl}$, the majority of the rods did not exceed $15 \mu$ in length, but in the higher percentages there were large numbers of very long filaments.

\section{Fission.}

The method of fission was studied in an agar hanging block culture $(1$, p. 110). The smear on the block was made from a suspension in water of a four days' old culture in $2 \%$ dextrose broth. During the observations the rods were exposed to a brilliant light from a Nernst microscope lamp. The temperature of the room was $25^{\circ} \mathrm{C}$., but in the vicinity of the microscope varied from $27^{\circ}$ to $30^{\circ} \mathrm{C}$. owing to the heat from the lamp before mentioned. The lenses used were $\frac{1}{12} \mathrm{~mm}$. Zeiss immersion and No. 12 compensating ocular; with these the changes in the shape and grouping of the organisms could be quite easily followed. Observations were made every five minutes and drawings with the camera lucida about every fifteen minutes.

At 11.15 a.m. two individuals were singled out for study which were lying close together and were apparently the result of the division of a single rod (Plate XII, fig. a).

For the first $1 \frac{1}{2}$ hours, there was very. little change beyond a slight increase in the length of both rods. At 12.55 there was a slight constriction in the middle of one of them (fig. $b$ ); a transverse wall was formed and at 1.10 p.m. the division was complete (fig. c). The second rod increased to nearly three times its original length and then divided in a similar way (figs. $f, g$ ). After this, all the individuals under observation continued to divide rapidly; about 15 minutes elapsed from the first sign of constriction to the completion of division and in another 20 minutes the two new rods thus formed had attained their maximum size and had begun to divide again. The segments were not always of equal size. 
Each rod as soon as it divided, pushed away and became completely separated from its neighbour. By a careful adjustment of the illumination, a delicate capsule could be detected surrounding each and preventing close contact.

The small colony which was being formed from the two rods originally selected was kept under observation until 4.30 p.m., when it consisted of 28 rods. At this time other colonies on the agar hanging block numbered 2--24 individuals. In most cases these were the result of the division of a single rod.

At 9 a.m. on the following morning the colonies were easily visible to the naked eye. Under the low magnification their structure was grumose.

Development in the agar hanging block was comparatively slow, doubtless owing to the fact that growth was anaerobic and that for part of the time took place under very strong illumination. After 24 hours the colonies appeared to the naked eye as small white pin spots, whereas a poured plate kept in the incubator at $30^{\circ} \mathrm{C}$. for the same length of time developed surface colonies $5-7 \mathrm{~mm}$. in diameter. The submerged colonies, however, were very little larger than those developed on the hanging block.

\section{Grouping.}

In young cultures on agar and gelatine, the rods are usually single, but in liquid cultures they frequently occur in pairs.

In the pellicle on the surface of beef broth cultures, chains are formed; these are composed of elements similar to the single rods and may comprise from 2-40 individuals. The chains are straight or curved (Plate XIV, figs. $a$ and $b$ ) and very easily fall apart. There are no chains in the sediment which forms when the tube is in any way disturbed and the pellicle sinks to the bottom.

The chains are not disposed in any particular way, but the orientation is irregular.

\section{Internal structure.}

Young, actively dividing rods stain very evenly, but in the older cultures some changes of structure can be observed.

Rods from a ten days' old culture in $2 \%$ dextrose broth when examined with the paraboloid condenser frequently show one or several highly refractive granules (Plate XIV, fig. $c$ ). In preparations made from very old agar cultures to test for the presence of spores, some of 
the rods contained small bodies which stained red by Moller's spore stain.

In the sediment of old broth cultures, the rods stain very unevenly, and are apparently vacuolated. Numbers of them have a large central vacuole with a deeply staining portion at each end. In others, there are several bands of colour across the organism in addition to those at the poles.

$$
\text { Capsules. }
$$

It has already been mentioned that a delicate capsule could be detected round rods growing on beef broth agar. This was still more evident with dark ground illumination.

In the ring formed round the tube at the surface of liquid broth $(1 \times 15 \mathrm{~F}$.) cultures, there are numerous organisms with a very definite capsule (Plate XIV, fig. $d$ ).

When stained by MacConkey's method, these capsuled bacilli take the stain mush more deeply than the others; the capsule is unstained and shows as a colourless ring surrounded by the slimy mass in which it is embedded; the latter takes the stain and appears granular.

\section{Spores.}

Cultures of various ages and on numerous media were examined for spores but none were detected.

\section{Motitity.}

In young cultures on agar and in liquid media, the organism is actively motile. The bacteria move rapidly with a forward screw-like movement which does not continue long in the same direction. The rod after proceeding for some distance turns and darts in a different direction, or its progress is interrupted by tumbling movements or by rotation on its long axis. The motile rods are usually single, but fairly frequently pairs may be seen in motion, or occasionally short chains. These move forward in a sinuous manner.

That flagella are present may be seen by using the paraboloid condenser with a Zeiss a pochromatic objective $3 \mathrm{~mm} .95$ ap. The number and position of the flagella cannot be ascertained, however, as they are in rapid motion, although it is evident that there are several and that they are peritrichous.

When observed under a cover glass, after a while the majority of the rods make their way to the edge of the preparation or to an air 
bubble where they remain in feeble motion; the remainder gradually come to rest.

The flagella stain fairly easily by van Ermengen's method. They are three to eight in number, peritrichous, slender and $5-7$ times the length of the rod (Plate XIV, fig. $e$ ). A more satisfactory and simple method of staining was found in one described in detail by Ellis (7). This is a modification of Löfler's flagella stain; it is a very simple method and gives a clear stain on a ground almost free from precipitate. I have failed to stain the flagella by the original method of Löfler, or by Pitfield's method.

\section{Involution forms.}

The long threads found in cultures containing large percentages of $\mathrm{NaCl}$ may possibly be termed involution forms. Some of these are curved and others are swollen irregularly (Plate XIII, fig. a). A drop of \pm 15 beef broth was placed on a cover glass, inoculated with rods from a beef-broth culture containing $8.5 \% \mathrm{NaCl}$ (Plate XIII) and inverted over a moist chamber. The drops contained a couple of dozen rods of varying length and form; the rod shown to the right of fig. $a$ was selected for observation.

In 30 minutes two septae had formed and ten minutes later the rod separated into three distinct lengths (fig. $c$ ). These two stages were observed with the $\frac{1}{12}$ th oil immersion (Zeiss) and No. 12 compensating ocular and were drawn with the camera lucida. At this point, however, the rods moved into a deeper part of the drop and it was not possible to get them into focus with the oil immersion. The observation was therefore continued with the Zeiss objective $\mathrm{D}$ and compensation ocular No. 18. The drawings were done freehand as near as possible to the scale of the first two.

The portions of the original filament now divided fairly rapidly into segments of very unequal length, and after three hours they became approximately the normal size of the bacillus (figs. $d-g$ ). At this time, the rods being small and rather numerous, they scattered, and it was impossible to trace them further as they became intermingled with bacilli resulting from the division of other filaments.

Some of the rods divided into much more equal segments than the one selected for observation, and the segments remained in contact longer. Fig. $h$ shows an exceptionally long one and two shorter ones which had divided in this way. 
The long filaments are not rigid and changes of form are frequently observable through curving in various directions.

The culture was exposed to the light of a Nernst lamp during the period of observation and the temperature of the room was $26-27^{\circ} \mathrm{C}$.

The slide was placed in the incubator at $30^{\circ} \mathrm{C}$. during the night and was again examined the following morning, 22 hours after the culture had been made. The drop was crowded with rods of normal size; in the centre was a thick clump, cochleate in form, but all the outlying rods were in active motion.

\section{Staining reactions.}

The organism stains well with all the ordinary aniline dyes; it stains deeply with dilute aqueous solutions of methylene blue, basic fuchsin, thionine and gentian violet; and still more intensely with carbol fuchsin and carbol gentian violet. The last named seems to be the best stain for general purposes.

The bacillus is not acid fast, i.e. it stains blue by the Ziehl-Neelson method but is Gram-positive, and also stains by Claudius' method which has recently been recommended for use in place of Gram's method (2).

When stained by Neisser's method, the bacilli are light brown, and many of them show a small black granule at each pole which is stained with the acid methylene blue. The rods which showed this reaction had been grown on Löffler's blood serum and incubated at $37^{\circ} \mathrm{C}$. for 18 hours.

\section{Cultural characters.}

In all cultures made for the observation of morphological and cultural characters, preliminary cultivation was practised as prescribed in the chart issued by the Society of American Bacteriologists (1), except that as growth was very slow at $20^{\circ} \mathrm{C}$. the cultures were incubated at $25^{\circ} \mathrm{C}$. In describing the topography of the colonies, terms are used as defined by" Chester (4) and the references following names of colours are to the numbers of the plates in which the corresponding colours can be found in Ridgway's Colour Standards and Nomenclature (12).

Nutrient Agar Colonies. Nutrient agar ( +15 Fuller) was found to be a suitable medium for general purposes. The most characteristic colonies are developed at a temperature of $25^{\circ} \mathrm{C}$. They are visible after 24 hours, when they are shining white, circular bodies 1 to $1.5 \mathrm{~mm}$. in diameter; even at this early stage the margin of some of them is becoming undulate; they are denser at the centre than towards the 
circumference and, when examined microscopically, are granular in texture. The submerged colonies are minute, irregular in form and granular (Plate XI, fig. a).

After 48 hours the colonies are $1-2 \mathrm{~cm}$. in diameter, rather irregular in form and with a lobate margin. There is a dense spot in the centre surrounded by one or two concentric rings. The colour is white by reflected light, and a coppery tint by transmitted light. The colonies do not increase in size after this, but change somewhat in colour and texture up to the fifth day; at this time the colour is maize yellow or buff yellow (IV, $V O-Y, f-d$ ) and the colony is surrounded by rather a heavy margin (Plate XI, fig. a); the surface is smooth and shining, and slightly raised.

In thickly sown plates the colonies are irregularly circular, with a less deeply lobed or almost smooth margin.

At $30^{\circ} \mathrm{C}$. the form of the colonies is somewhat different; they attain a diameter of $1-5 \mathrm{~mm}$. in 24 hours. They are opalescent by transmitted light, with some concentric rings, finally becoming yellow as at $25^{\circ} \mathrm{C}$. The maximum diameter is $6-10 \mathrm{~mm}$. and the colonies are irregularly circular with a heavy margin.

At $37^{\circ} \mathrm{C}$. growth is also rapid, the colonies are more opalescent than at $30^{\circ} \mathrm{C}$. and the concentric rings are more conspicuous. When mature, the colonies are circular and the margin smooth; the colour is slightly deeper than at the lower temperature. The centre of the colony is very slightly raised, and in some there is a heavier ring about $1-2 \mathrm{~mm}$. from the edge, with radiations towards the margin.

The growth at $20^{\circ} \mathrm{C}$. is comparatively slow. Colonies are only just visible to the naked eye after 24 hours when they consist of a dense white spot surrounded by a translucent margin. At this temperature thin, spreading colonies are finally formed $7-8 \mathrm{~mm}$. in diameter. They are irregular in shape, and no definite yellow colour is developed; the colonies remaining a creamy tint $(19$ yo-y).

In old plate cultures, especially those at the higher temperatures, there are numerous $\mathbf{X}$-shaped crystals formed (Plate XI, fig. $b$ ). In all young cultures when examined microscopically, a swaying movement is noticeable right through the colony, due to the activity of the rods composing it.

Nutrient agar streak. On nutrient agar with a reaction of +15 Fuller, there is quite a plentiful growth after 24 hours at $30^{\circ} \mathrm{C}$. It takes the form of a glistening homogeneous streak along the needle track which is somewhat opalescent by transmitted light, milky white by reflected light. 
After 48 hours streaks average $\frac{1}{2} \mathrm{~cm}$. in width, but taper gradually from a breadth of about $\frac{3}{4} \mathrm{~cm}$. at the bottom of the tube to a point near the top of the medium. The difference in the luxuriance of the growth at different levels is no doubt due to difference in the amount of moisture in the medium. The edge is smooth and there is a homogeneous translucent margin about $1.5 \mathrm{~mm}$. wide all round the growth, the central part has become more dense and granular. In some of the tubes there are small opaque spots in this central portion or else longitudinal lines of a similar nature.

The streaks do not usually exceed $1 \mathrm{~cm}$. in width when growth ceases, but if the surface of the agar is very moist, sometimes a spreading growth is formed which almost covers the surface of the agar. Occasionally there is a tendency to form discrete colonies.

The yellow colour is visible after four days, being similar to that developed in the plates. The edge of the growth also becomes heavier than the central portion. The surface is always shiny, and when the medium is becoming rather dry it looks almost like varnish. A heavy yellow sediment forms at the bottom of the condensation water, and on the surface of it there is a pellicle which adheres to the glass tube on the side remote from the slant agar.

The colour of streak cultures is often a little deeper than that of colonies, and varies from buff-yellow to apricot yellow (IV, 19 YO$Y d-b)$. In old cultures $X$ and $Y$-shaped crystals are formed starting from the surface of the medium and pointing down into the agar. The surface of the agar becomes whitish. There is no noticeable odour.

Nutrient agar stab. There is very little growth in the depth of the medium, only a thin white line following the needle track. A fairly large round colony is formed on the surface of the agar.

Glucose formate agar. A number of cultures were made on this medium as controls to anaerobic cultures. The growth is similar to that on nutrient agar, but if anything more luxuriant and slightly deeper in colour. Crystals are very frequently formed in this medium.

Mango agar. The growth on agar made from an extract of mango fruit was somewhat similar to that on beef-broth agar, but the culture is cream coloured and never becomes yellow. It consists of a glistening streak along the needle track, with smooth edges and very much raised surface.

Treacle agar. The organism only made a very feeble growth on this medium. 
Sol. N. with agar. On Marshall Ward's Solution N. solidified with agar the organism grew fairly well for the first 24 hours, but did not subsequently extend very much. There was no chromogenesis; the streak did not exceed $4 \mathrm{~mm}$. in breadth, and was granular round the edges.

The bacillus grew out into very long threads on this medium, but the filaments did not show the irregularities characteristic of those grown in $\mathrm{NaCl}$ solutions.

Nutrient gelatine (+15 Fuller) colonies. When incubated at $20^{\circ} \mathrm{C}$., colonies on nutrient gelatine are just visible to the naked eye after 24 hours. After 48 hours the superficial circulars are $\frac{1}{2} \mathrm{~mm}$. to $\frac{3}{4} \mathrm{~mm}$. in diameter. They are circular, white and glistening, and the surface being very much raised they have the appearance of small drops of milky water. The submerged colonies are smaller and irregular in outline. All are granular as seen with the microscope under a low magnification.

In three days the surface colonies have increased still further in size; they are circular to ellipsoid, and measure up to $1 \mathrm{~mm}$. The smaller colonies are capitate, the larger ones raised; the margin is wavy and texture coarsely granular; a yellowish tinge is becoming evident, and there is just an indication of liquefaction round the edge of the colonies. The submerged colonies are punctiform to the naked eye; when examined under magnification the majority are spherical, though a few are irregular in outline; they are granular in texture, dense in the centre and thinning out to a pellucid margin.

The surface colonies can be lifted out entire on the point of a needle. When mounted in water and examined microscopically, the bacteria diffuse very slowly from the compact mass, but those which escape into the water are very active.

After seven days, the surface colonies measure $1-3 \mathrm{~mm}$., and submerged colonies $1-\frac{3}{4} \mathrm{~mm}$. in diameter. The former are very much raised, somewhat moruloid, yellow and with irregular margin; the shape is also irregular.

After ten days, each of the surface colonies is sunk in a little saucer of liquefaction, and after 17 days the gelatine is completely liquefied. The yellow colonies are still entire and floating in the liquid medium, though larger and looser in texture than formerly. The colour is similar to, but slightly deeper than, that developed in the agar colonies.

At $12-15^{\circ} \mathrm{C}$. similar results were obtained, but growth was decidedly slower. Colonies were not visible to the naked eye until after 48 hours: 
the first distinct evidence of liquefaction (colonies crateriform), was noticed after 14 days, and liquefaction was complete in about 24 days.

Nutrient gelatine stab. A number of stab cultures, made in +15 nutrient gelatine in test tubes measuring $7 \times 1^{\prime \prime}$ and incubated at $20^{\circ} \mathrm{C}$., showed the following characters.

After 48 hours at $20^{\circ} \mathrm{C}$, the needle track was just distinguishable; a thin line of white growth extending to the bottom of the tube. Three days later the growth in the deep parts of the gelatine was seen to consist of very numerous and minute spherical colonies. On the surface of the gelatine there was a colony about $4 \mathrm{~mm}$. in diameter and rather deep coloured.

In nine days the surface growth had sunk in a little saucer of liquefaction, and under this there was a hemisphere of liquefied, clouded gelatine. Five days later the top of the liquefied portion was $1 \mathrm{~cm}$. in diameter; the surface colony remained entire, floating on the liquefied gelatine. Its centre was deep coloured, but it was lighter towards the margin. The shape of the whole growth was napiform, $1.5 \mathrm{~cm}$. wide at the broadest point. There was a sediment at the bottom of the liquefied portion.

In twenty days from the time of inoculation the growth had extended to the width of the tubes and the liquefaction to a depth of $2 \mathrm{~cm}$. (Plate XI, fig. c). The cloudy, liquefied portion continued to increase in size, became infundibuliform in shape (Plate XI, fig. $d$ ), then extended downwards and finally completely liquefied the gelatine.

The colour of the surface growth was deep chrome (Plate III, $17 \mathrm{O}-$ $Y, b)$ and that of the sediment light orange yellow. The culture had no distinctive odour.

In tubes inoculated at $25^{\circ} \mathrm{C}$. liquefaction commenced after six days and reached the stage shown in fig. $d$ in nine days.

Nutrient gelatine streak. Streak cultures on nutrient gelatine incubated at $20^{\circ} \mathrm{C}$. form a line of growth about $5 \mathrm{~mm}$. broad along needle track in three days. It is smooth, shining and yellow, and opalescent at the edges. In a short time liquefaction commences at the bottom of the streak, making a groove in the gelatine, and as it continues the melted gelatine runs to the bottom of the tube.

Nutrient gelatine shake. Shake cultures in nutrient gelatine developed very numerous, minute colonies near the surface of the gelatine becoming less numerous towards the bottom of the tube; they are evident after three days. Liquefaction sets in on the sixth day, beginning at the surface of the medium and working downwards until the whole is liquefied. 
Loffler's blood serum. Streak cultures on Löfler's blood serum at $37^{\circ} \mathrm{C}$. at the end of 18 hours show a shining, yellowish growth along the needle track; after 48 hours this becomes deep chrome yellow, forming a streak about $2 \mathrm{~mm}$. broad with smooth edges; it is shining and not raised above the surface of the medium. No liquefaction is observed in tubes kept under observation for several weeks.

Starch Jelly. There was no growth in starch jelly made with Uschinsky's solution even in tubes kept under observation for several weeks.

Potato. The first evidence of growth on potato cylinders is a slight, shining yellowish growth along the needle track; it then spreads over the lower, moist portion of the cylinder, but on the upper half there is no further growth. The colour is buff yellow (IV). There is no greying or other discolouration of the medium.

Mango. On pieces of mango sterilised by steaming in Roux tubes the organism forms a cream-coloured, spreading growth covering the surface of the medium. The mango was not discoloured.

Cocoanut. This is a good medium for chromogenesis, but a plentiful growth is not obtained unless the medium is moist. At $25^{\circ} \mathrm{C}$. and $30^{\circ} \mathrm{C}$. growth was just visible in 24 hours, first appearing as a shining streak along the needle track; in 48 hours a glistening, cream-coloured growth covered all the lower part of the cylinder. This was the wettest part of the medium, as the pieces of cocoanut were steamed in Roux tubes whose bulb was filled with water, or in ordinary test tubes resting on a wad of wet cotton wool. In three days the colour was slightly deepened, the water in the bulb of the Roux tubes clouded, and in tubes where the cocoanut was resting on cotton wool, the upper layers of this substratum were slightly yellow. The colour deepened and became buff yellow (IV. 19 YOI-Y,d). In the Roux tubes, a yellow sediment formed at the bottom of the bulb, and a ring on the glass just above the liquid. As soon as the medium began to dry up growth ceased, and no further changes took place in the appearance of the culture.

Beet. Tubes containing cylinders of beetroot were prepared in a similar way to those containing cocoanut. The organism grows very vigorously on beet; the whole of the cylinder became covered with it shining, wet-looking growth, the upper part having a granular appearance, and the lower portion being wrinkled. In the Roux tubes a heavy pellicle was formed on the surface of the water in the bulb, and in the straight tubes where the cylinder was resting on wet cotton wool 
the surface of the latter was covered with a yellow wrinkled growth. The colour was deeper than on most media, varying from light orange yellow to deep chrome (III 17, $O-Y, d-b$ ).

Carrot. This was not a favourable medium, a thin spreading growth covered the moist parts of the cylinder.

Nutrient broth $(+15$ Fuller). The bacillus grows very vigorously in nutrient broth; at $30^{\circ} \mathrm{C}$. a slight clouding is visible in $6-8$ hours; after 24 hours a ring begins to form above the surface of the liquid, and in 48 hours it is well formed and yellowish in colour. A thin pellicle forms on the surface of the broth, and this sinks to the bottom if the tube is slightly shaken and forms a sediment. After three months the broth becomes almost clear, the ring has dried on the sides of the tube, and all of the pellicle fallen to the bottom.

The ring formed above the surface of the broth is very tough and slimy; it is almost impossible to break it with a platinum needle. Cultures in nutrient broth had no noticeable odour.

In broth containing $2 \%$ dextrose, similar results are obtained, but the clouding is heavier; in a medium containing $6 \%$ glycerine, on the other hand, there is a much less copious growth.

Dunham's solution. The bacillus does not grow well in peptone water, but this medium becomes slightly clouded in 48 hours. There is no pellicle and no sediment.

Litmus milk. The tubes when inoculated were deep lavender in colour (XXXVI) and the controls did not change during the time that they were kept under observation.

The organism grows very slowly in milk tubes, and it was not until the tenth day that there was any decided change. After 12 days at $25^{\circ} \mathrm{C}$. the colour was pale lilac (XXXVII); on the 16 th day it was flesh pink (XIII), and this change of colour was accompanied by a curd-like coagulation of the casein with a separation of whey.

At $30^{\circ} \mathrm{C}$. a similar coagulation took place after the same lapse of time, but the reaction was not so acid, the colour being pale cinnamon pink (XXIX). At these two temperatures no further change of colour took place, nor was there any solution of the curd; but after 25 days the colour was completely reduced in all the tubes.

At $37^{\circ} \mathrm{C}$. the medium did not turn pink, but after 12 days the colour was completely reduced. The casein coagulated but there was no extrusion of whey. The curd was then gradually dissolved, and after 27 days all that remained was a clear yellow fluid with a slight bacterial sediment at the bottom of the tube. 
Uschinsky's solution. The bacillus would not grow in this solution.

Cohn's solution. A slight clouding took place after three days. No ring or pellicle formed, and there was no sediment.

Beerwort. The tubes were kept under observation for a considerable length of time, but they remained clear.

Potato broth. Abundant growth took place in Appel's potato broth. A ring and pellicle were formed.

Cabbage broth. In cabbage broth the organism caused very heavy clouding; there was not much pellicle, but a fairly wide ring formed, and there was about $\frac{1}{2} \mathrm{~cm}$. of sediment at the bottom of the tubes. The upper part of the ring was yellow, but the lower part, which was in contact with the broth, was light salmon orange (11). The sediment was the so ne peculiar colour.

Beet juice. Very heavy clouding took place in this medium, the ring and pellicle were very well developed in colour, the growth was similar to that formed on solid beet.

Salution N. A fair amount of growth was observed in Marshall Ward's Solution N, the medium clouded, but there was no formation of ring or pellicle.

\section{Physical and Biochemical Features.}

In this section of the work, unless otherwise stated, the methods used are those outlined by Eyre (8). Each of the tests was repeated several times, and in no case were the results contradictory, although they varied slightly with the vigour of the culture used. Even where not specially mentioned, each experiment was checked by the use of controls.

Enzyme production. The organism is capable of dissolving the middle lamella of cells in the tissues of the host plant, but it has apparently no action on cellulose.

A series of experiments conducted to test for the presence of various enzymes in cultures of the bacillus, for the most part led to negative results. A brief outline of these experiments follows.

Diastatic enzymes. Four tubes of nutrient broth of optimum reaction were inoculated and incubated for five days at $30^{\circ} \mathrm{C}$. The cultures were removed from the incubator on the fifth day, and mixed with equal quantities of starch paste containing $2 \%$ of thymol; they were then placed in the incubator at $37^{\circ} \mathrm{C}$. for six hours, and at the end of that time were tested for sugar with Fehling's solution. There was no reaction for sugar. 
Cylinders of potato on which the organism had been growing for ten days or longer, when tested with iodine gave the purple red reaction characteristic of amylodextrin, but did not reduce Fehling's solution.

Invertin enzymes. Tube cultures in nutrient broth were prepared and incubated as in the previous experiment. At the end of the incubation period the cultures were mixed with an equal quantity of a $2 \%$ solution of saccharose containing $2 \%$ phenol and allowed to stand for six hours. When tested at the end of this time, it was found that the mixture did not reduce Fehling's solution, therefore there were no invertin enzymes present.

Rennet and lab enzymes. Tubes prepared and incubated as before were heated at $55^{\circ} \mathrm{C}$. for 30 minutes, in order to sterilise them without destroying any enzymes which might be present. After this $5 \mathrm{cc}$. of the culture was run into each of three tubes of sterile litmus milk. No coagulation or change of any kind was observed in these during ten days at $20^{\circ} \mathrm{C}$.

Acid production. There is no very marked change in the reaction of any liquid medium in which this bacillus is grown. A series of flasks containing nutrient broth with $2 \%$ lactose, saccharose, glycerine, laevulose and dextrose were inoculated and kept at a temperature of $30^{\circ} \mathrm{C}$. for ten days; at the end of that time the cultures were slightly more acid than the controls, but only by 2-5 degrees of Fuller's scale.

A test for organic acids was also made, using 500 cc. of $2 \%$ dextrose broth in which the organism had been growing for ten days. The only reaction obtained was a rather doubtful one for succinic acid.

Alcohol production. The first distillate of a ten days old culture in $2 \%$ dextrose broth was divided into three portions.

To the first was added Lugol's iodine solution, then a little $\mathrm{NaOH}$ solution. There resulted a smell of iodoform indicating the presence of alcohol, acetone or an aldehyde. A small quantity of Schiff's reagent was pipetted into the second portion; in the greater number of cultures tested there was no reaction, but in one case a faint pink colour appeared, and there was probably a trace of aldehyde in the culture.

To $10 \mathrm{cc}$. of the third portion was added $10 \mathrm{cc}$. of $\mathrm{H}_{2} \mathrm{SO}_{4}$ and $1 \mathrm{cc}$. of a $4 \%$ solution of potassium permanganate. On adding Schiff's reagent, after five minutes a decided red colour was developed, indicating the presence of alcohol. A decided reaction for alcohol was obtained repeatedly in the distillate from cultures in $2 \%$ dextrose broth.

Ammonia. Two flasks of nutrient broth were prepared, each containing $100 \mathrm{cc}$. One of these was inoculated, and both were put in the 
incubator at $30^{\circ} \mathrm{C}$. After ten days, 2 grams of calcined magnesia were added to each flask, and $50 \mathrm{cc}$. distilled from each. Neither of the distillates gave any reaction for ammonia with Nessler's solution. Ammonia is sometimes produced in media containing a nitrate, but this point will be discussed under the heading "nitrate reduction."

Indol and phenol. Tubes of peptone water in which the organism had been growing for ten days at $30^{\circ} \mathrm{C}$, always gave a distinct reaction for indol with sulphuric acid and potassium nitrate, there was no such reaction in the controls.

A culture in a flask containing 300 cc. of nutrient broth was used to determine the presence or absence of phenol. After ten days at $30^{\circ} \mathrm{C}$. the contents of the flask were tested for indol and phenol as follows. After adding $50 \mathrm{cc}$. of $\mathrm{HCl}$, the flask was connected with a condenser and $50 \mathrm{cc}$. distilled over. The distillate was rendered strongly alkaline with $\mathrm{KOH}$ and redistilled. The distillate tested with sulphuric acid and potassium nitrite gave a decided reaction for indol.

The residue, when cold, was saturated with $\mathrm{CO}_{2}$ and redistilled. This third distillate gave no reaction for phenol with Millon's reagent or with ferric chloride. A control flask, similarly tested, gave no reaction either for indol or for phenol.

Pigment production. It has been stated in connection with the description of the cultural characters of the organism that it is capable of producing a yellow pigment on a variety of media; and that this pigment develops more rapidly at $30^{\circ}-37^{\circ} \mathrm{C}$. than at lower temperatures. The colouring matter is insoluble in water, hot or cold, in alcohol, ether, chloroform or dilute acids.

Colour reduction. The organism was grown in nutrient broth tinted with various coloured substances; a number of trials were made in each, but a typical set of tubes is selected in each case for detailed description. In all the experiments the colour of the control tubes remained unchanged.

Litmus. The reduction of litmus in milk cultures has already been described. The colour is also reduced in nutrient broth with or without the addition of dextrose. In a vigorous culture reduction is complete in 48 hours at $30^{\circ} \mathrm{C}$., but with a less vigorous strain of the bacillus the process was much slower and took as long as six days.

In one instance the tubes before inoculation were bishop's purple (XXXVII), in 24 hours the reaction of the tubes was more acid, and the colour scarlet red (I). The following day reduction had commenced, working from the bottom of the tube; the lower half of the broth was 
light salmon orange (II), and the upper half peach red (1). After three days the upper third of the tube only retained any colour and in five days it was colourless. The only considerable variation in this process was in the length of time which it occupied; the medium in every case became slightly acid and then bleached out from the bottom upwards.

Neutral red. Tubes of nutrient broth tinted carmine (I) with this stain were inoculated and incubated at $30^{\circ} \mathrm{C}$. The organism grew well in this medium, and a fairly heavy ring formed round the tube at the surface of the liquid. The cultures were kept under observation for ten days, but no reduction took place. The bacterial ring absorbed the colouring matter and became carmine. Rods from this ring when mounted in water and examined microscopically were faintly stained; there were some short capsuled rods, and some long filaments of rather uneven breadth similar to those found in media containing $\mathrm{NaCl}$.

Rosolic acid. The colour of the medium at the beginning of the experiment was peach red (I). After 24 hours at $30^{\circ} \mathrm{C}$. the colour was bittersweet orange (II), and it subsequently passed through buff (III) to light orange yellow (II). In six days the culture was entirely colourless except for the bacterial ring at the surface of the liquid which had absorbed the colouring matter and become orange red. The stain was not in this case sufficiently intense to be evident in the bacilli when they were examined microscopically.

Methylene blue. A number. of tubes and fermentation tubes were prepared containing broth tinted with methylene blue to the colour of a strong ammoniacal solution of copper sulphate. The closed arm of the fermentation tube was colourless after sterilisation and remained so throughout the experiment; the description of changes of colour therefore refers to the ordinary test tubes, and to the open arm of the fermentation tubes.

As in the case of tubes coloured with litmus solution reduction commenced at the bottom of the tubes. After the cultures had been kept at $30^{\circ} \mathrm{C}$. for 24 hours the lower part of the tube was colourless and the upper part Tyrolite green (VII). On the second day there was only about $\frac{1}{2} \mathrm{~cm}$. at the surface of the liquid which retained the green colour. After six days the medium was colourless, but the bacterial ring had partially absorbed the colour and was Venice green (VII).

The colour did not return at all when the tubes were shaken.

Indigo carmine. Indigo carmine was also gradually reduced from the bottom of the tube upwards. In this case the organism did not absorb the colouring matter. Reduction was complete in eight days. 
Congo red. Congo red was not reduced, but the dye was absorbed by the superficial bacterial growth as in the case of neutral red.

Cultures were made in nutrient broth tinted with several other dyes, chiefly in order to determine whether any of these would inhibit the growth of the organism. None of them actually inhibited the growth in very dilute solutions, but growth was feeble in broth containing malachite green or cyanin.

The bacillus grew well in Trypan blue, and completely reduced the colouring matter; Trypan red was not reduced, but the surface growth absorbed the stain.

Reduction of nitrates. Nitrates were more completely reduced when the organism was grown in nitrate water than when it was grown in nitrate broth.

A flask of nitrate water $(8$, p. 169$)$ was inoculated from a young culture of the organism in nutrient broth and incubated with a control flask at $30^{\circ} \mathrm{C}$. for five days. The culture was then divided into four portions, the first two being used to test for the presence of nitrites. There was no reaction for nitrites when tested by the iodine-starch method or with a-naphthylamine and sulphanilic acid.

A third portion tested with Nessler's solution developed a distinct yellow colour indicating the presence of ammonia. The remainder of the culture was evaporated to dryness and tested for the presence of nitrates with phenolsulphonic acid. There was no reaction.

The nitrate water in the control flask tested in a similar way gave a distinct reaction for nitrates but none for nitrites or ammonia.

The test for nitrate reduction was repeated using nitrate broth $(8$, p. 143) in place of nitrate water. The culture and control were tested on the fifth day in the manner described above and as before the control was found to contain nitrates but no nitrites or ammonia. The culture reacted strongly both with iodine and starch paste, and with a-naphthylamine and sulphanilic acid showing the presence of nitrites; there was no reaction, however, for nitrates or ammonia.

Fermentation tubes. The organism was grown in fermentation tubes containing $2 \%$ sugar broth, but there was no gas production with any of the carbohydrates used. In one solitary case gas was formed from dextrose and saccharose, but this proved to be due to the presence of an interloper. The vigour of growth in the open and the closed end varied greatly with the composition of the medium. The intensity of clouding 
in media containing various carbohydrates is shown in the following table:

$\begin{gathered}\text { Carbohydrate } \\ \text { used }\end{gathered}$
Dextrose
Saccharose
Laevulose
Maltose
Raffinose
Galactose
Mannite
Lactose
Dextrin
Glycerine

Clouding in
closed arm
heavy
hesvy
moderate
moderate
slight
very slight
slight
none
very slight
none

Clouding in
open arm
very heavy
very heavy
heavy
heavy
heavy
moderate
heavy
fairly heavy
very heavy
moderate

It will be noticed from this summary, that the organism does not grow anaerobically in the presence of glycerine and lactose, and only feebly in the presence of galactose and dextrin.

Hydrogen sulphide. Tubes of peptone lead solution (8, p. 186) were prepared in order to test for the presence of $\mathrm{H}_{2} \mathrm{~S}$. Cultures in this medium were kept under observation for sixteen days, but there was no formation of hydrogen sulphide; the precipitate was not blackened. At the end of sixteen days the cultures were discarded.

Toleration of $\mathrm{NaCl}$. The bacillus can grow in media containing comparatively large percentages of sodium chloride. A number of tubes containing various percentages of $\mathrm{NaCl}$ (from $.5 \%$ to $10 \%$ ) in +15 nutrient broth were inoculated from a young culture and incubated at $30^{\circ} \mathrm{C}$. Tubes containing less than $4 \% \mathrm{NaCl}$ were clouded in 18 hours, while those containing from $4 \%$ to $8.25 \%$ were clouded in 48 hours. In tubes containing $9 \%$ and over there was no growth; in the $8.5 \%$ and the $8.75 \%$ solution the clouding was so slight as to be barely noticeable, but a microscopic examination showed that the organism had multiplied considerably. The abnormal forms found in this medium have been described elsewhere.

Reaction of medium. The organism is not particularly sensitive to the reaction of the medium in which it is grown. The optimum is about +17 of Fuller's scale, but there is very little variation in the rapidity of growth in media of reactions varying from +14 to +23 Fuller. During an experiment undertaken to find the optimum reaction, broth tubes having these reactions clouded in six hours at $30^{\circ} \mathrm{C}$; 估ose with a reaction of +2 to +14 and from +24 to +27 Fuller clouded in seven hours; those with reactions from +28 to +30 and from +10 to +1 in eight hours. In tubes containing more alkaline broth growth 
was considerably slower, the organism preferring a medium which is slightly acid to phenol-phthalein.

A series of cultures was made to test the ability of the bacillus to geor in media containing varying quantities of certain acids and alkalis.

To flasks containing $50 \mathrm{cc}$. of neutral broth were added different percentages of acetic, oxalic, tartaric, and malic acids, and of sodium hydrate and sodium carbonate. With each of these substances a series of flasks was prepared varying in reaction from 0 to \pm 50 of Fuller's scale, the intervals between the reactions of any two in a series being five degrees, so that there were ten flasks in each series. The contents of each flask were pipetted into four tubes and these wero sterilised. A loopful of a young broth culture was introduced into three tubes of each set and the fourth kept as a control. The results obtained from the observation of these cultures may be tabulated as follows, the controls in every case remained clear.

$\begin{array}{lcc}\text { Substance tested } & \begin{array}{c}\text { Amount to } \\ \text { retard growth } \\ \text { Reactions in terms of Fuller's gcale }\end{array} & \begin{array}{c}\text { Amount to } \\ \text { inhibit growth }\end{array} \\ \text { Aoetio acid } & +25 & +30 \\ \text { Oralio acid } & +30 & +35 \\ \text { Tartario acid } & +35 & +40 \\ \text { Citric acid } & +30 & +40 \\ \text { Malio acid } & +35 & +36 \\ \text { Sodium hydrate } & -30 & -45 \\ \text { Sodium carbonate } & -30 & -36\end{array}$

Atmosphere. That the organism is a facultative anaerobe was suggested by the fact that it grew in the closed end of fermentation tubes and in the depth of the medium in stab cultures, though in the latter growth is never abundant. A series of cultures was therefore made to test the ability of the bacillus to grow in the absence of oxygon and in the presence of various other gases. Bulloch's apparatus was used in making most of the anserobic cultures, and the method used in each case was similar to the one now to be described; slight variations in method were of course necessary in order to introduce the various gases into the apparatus, but these are mentioned in connection with the individual experiments.

Oxygen and carbon dioxide absorbed. Streaks were made on slant nutrient agar and glucose formate agar, and a loopful of a young broth culture introduced into tubes of nutrient broth and gluoose formate broth. These were placed in a beaker standing in a glas basin at one 
side of which was placed a small heap of dry pyrogallic acid. The whole was next put inside the Bulloch's apparatus, the bell jar carefully sealed on to the ground glass plate and the air partially exhausted from the apparatus by attaching the exit tube to a suction pump. A strong solution of $\mathrm{KOH}$ was then siphoned into the glass basin without admitting air, dissolving the pyrogallic acid. A strong alkaline solution of pyrogallic acid was thus formed which absorbed the oxygen and carbon dioxide within the bell jar.

The apparatus was kept at a temperature of $30^{\circ} \mathrm{C}$. with a number of control tubes. In 48 hours there was a very vigorous growth in all the control tubes; the growth in the tubes deprived of oxygen was exceedingly slow as compared with that in the controls, and was not at all abundant.

This experiment was repested a number of times with similar results.

Hydrogen. A set of cultures was prepared and placed in the Bulloch's apparatus as described in the previous experiment. In this case, however, hydrogen was generated, and after being purified by passing through wash bottles containing solutions of silver nitrate, potassium permanganate and potassium hydrate, it was allowed to stream through the apparatus until all the air was expelled. Any oxygen or carbon dioxide remaining in the bell jar was absorbed as before with an alkaline solution of pyrogallic acid.

The growth in the tubes in the atmosphere of hydrogen was slightly better than in those kept in an atmosphere composed chiefly of nitrogen. This was found to be the case in two successive experiments.

A set. of tubes inoculated from hydrogen cultures and grown in Buchner's tubes in the absence of oxygen made better growth than the cultures deprived of oxygen which had been made direct from aerobic cultures.

Carbon dioxide. The apparatus was prepared in the same way as before and a current of carbon dioxide passed through it. In this case any remaining oxygen was absorbed by means of a solution of pyrogallic acid in water. There was a slight growth in all the tubes at the end of 48 hours, but not quite so much as in those grown in an atmosphere of hydrogen. Growth was abundant in all the control tubes.

Sulphur dioxide. In this case $\mathrm{SO}_{2}$ was passed through the apparatus until all the air was displaced before the introduction of the $\mathrm{KOH}$ solution. There was no growth in any of the tubes, nor did any growth 
take place when the tubes were removed from the apparatus and placed in the incubator, the organism having been killed by prolonged exposure to the gas.

The ability of the bacillus to withstand short exposures of $\mathrm{SO}_{2}$ was also tested. Transfers were made from a young culture to ten tubes of slant agar, a generous quantity of the culture being used. Two were placed in the incubator as controls, and the remainder were exposed to a stream of $\mathrm{SO}_{2}$ for periods varying from 15 seconds to five minutes. In tubes exposed for 15 or 30 minutes there was a slight growth along the needle track after five days; in those exposed for longer periods the organism was killed. Growth was abundant in the controls.

A drop of a liquid culture was introduced into each of eight tubes of nutrient broth, and a stream of $\mathrm{SO}_{2}$ passed through the tubes for periods varying from 15 to 60 seconds. There was no clouding in any of these.

Reduced pressure. A set of tube cultures was prepared and sealed in Bulloch's apparatus; then the air was exhausted as completely as possible from the bell jar. In this experiment the oxygen was not sboorbed

At the end of four days there was only a slight growth in the glucose formate agar and in the formate broth tubes, but quite a good growth in the tubes containing ordinary nutrient agar and broth.

Effect of germicides. In connection with the spraying experiments a series of cultures was made to determine the susceptibility of the organism to various germicides.

In testing substances which could be added to nutrient broth without causing precipitates the procedure was as follows: A young broth culture was used, one which had been kept at $30^{\circ} \mathrm{C}$. for 24 hours. From this $\cdot 1 \mathrm{cc}$. of the culture was dropped into each of a number of tubes of +15 broth, and this amount did not cause any clouding of the medium. Into the tubes thus inoculated, each of which contained exactly $10 \mathrm{cc}$. of broth, varying quantities of a solution of the germicides were pipetted, about five tubes being used for each percentage.

After remaining in the incubator at $30^{\circ} \mathrm{C}$. for 30 minutes a series of plates was poured from one tube in each group, the remaining four being returned to the incubator. The plates and tubes were kept under observation for a number of days until it was certain whether growth would take place or not. 
Only a few substances could be satisfactorily tested in this way, and the results obtained with these may be tabulated as follows:

\begin{tabular}{lccc}
\multicolumn{1}{c}{ Germicide } & $\begin{array}{c}\text { Amount to } \\
\text { retard growth }\end{array}$ & $\begin{array}{c}\text { Amount to } \\
\text { inhibit growth }\end{array}$ & $\begin{array}{c}\text { Amount to } \\
\text { kill organism } \\
\text { in 30 mins. }\end{array}$ \\
Formalin & $1: 20,000$ & $1: 10,000$ & $1: 1,000$ \\
Copper sulphate & $1: 1,500$ & $1: 1,000$ & $1: 200$ \\
Phenol & $1: 1,500$ & $1: 1,000$ & $1: 100$ \\
Sodium nitrate & $1: 25$ & $1: 10$ & \\
Kainite & $1: 25$ & $1: 10$ &
\end{tabular}

Lithium sulphate in the proportions of $1: 25$ had no effect in retarding growth. I did not find any involution forms in cultures containing $4 \%$ of this salt.

Substances which caused precipitates in nutrient broth were tested in a slightly different way. Tubes were prepared containing sterile distilled water with various percentages of the germicide. Into these - 1 cc. of a 24 -hour old broth culture was pipetted and they were allowed to stand at $30^{\circ} \mathrm{C}$. for thirty minutes. Plates were then poured as from the beef broth tubes in the previous experiment and these were kept under observation for several days.

The results obtained were as follows:

\begin{tabular}{|c|c|c|}
\hline Germicide & $\begin{array}{l}\text { Amount to kill } \\
\text { large percentage } \\
\text { of organisms } \\
\text { in } 30 \text { mins. }\end{array}$ & $\begin{array}{l}\text { Amount to kill } \\
\text { all organisms } \\
\text { in } 30 \text { mins. }\end{array}$ \\
\hline Mercuric chloride & $1: 20,000$ & $1: 10,000$ \\
\hline Hycol & $1: 2000$ & $1: 1000$ \\
\hline Formalin & $1: 2000$ & $1: 1000$ \\
\hline Cyllin & $1: 2000$ & $1: 1000$ \\
\hline Lysol & & $1: 400$ \\
\hline Copper sulphate & & $1: 400$ \\
\hline Potassium permanganato & $1: 400$ & $1: 350$ \\
\hline Iron sulphate & $1: 100$ & $1: 25$ \\
\hline Iron sulphide & $1: 75$ & $1: 25$ \\
\hline
\end{tabular}

From this table it is evident that the organism is most susceptible to mercuric chloride, but it was not considered advisable to make use of this substance for spraying owing to its highly poisonous nature.

The results of spraying with Hycol have been given in another part of the paper.

Action of sunlight. The organism is not sensitive to exposure to light. It grows well in the diffused light of the laboratory, though not so rapidly as in the dark. 
A series of thinly sown plates were exposed to direct sunlight, any undue heating being prevented by placing over each a glass basin containing about $2 \mathrm{~cm}$. of a $2 \%$ solution of potash alum. The number of colonies on plates exposed one to four hours was not appreciably less than the number developed in the control plates; there was a slight diminution in numbers in those exposed for five hours. This experiment was conducted in winter during the month of July.

Four cover glasses on which a film of bacilli had been dried were exposed to bright sunlight for one, two, three and four hours, then dropped into tubes of nutrient broth. Those exposed for one and two hours clouded the broth in 24 hours; those exposed three and four hours in $\mathbf{4 8}$ hours.

\section{Thermal Relations.}

The apparatus used for the determination of the thermal death point and figured below was adapted by Mr Ensor of the Public Works Department from a Hearson vacuum embedding bath intended for working with gas; it answers the purpose admirably, and regulates within one-tenth of a degree.

I am indebted to Mr Ensor for the following brief description of the apparatus and for the figure explaining the electrical connections:

Constant temperature water bath. The apparatus consists of the water bath of a Hearson vacuum embedding bath ( $A$, diagrams 1 and 2). This is electrically heated by means of two eclipse elements ( $L$, diagram 3) fixed to the bottom of the bath. The elements are connected in series on 250 volts.

For automatic regulation of temperature a switch $(B$, diagrams 1,2 and 3 ) actuated by a capsule ( $J$, diagram 3 ) is provided, this makes or breaks the heating circuit at the required temperature. A lamp ( $K$, diagram 3 ) is joined across the switch contacts to prevent sparking.

There is also a tumbler switch ( $C$, diagrams 1,2 and 3 ) by means of which the temperature can be controlled by hand if desired.

The water is continually stirred by means of a paddle $(D$, diagrams 1, 2 and 3) driven by a small motor $E$ fixed above the bath.

In order to cut down the speed of the motor to about 60 revolutions per minute a lamp ( $H$, diagram 3$)$ is connected in series. The speed can be varied by placing lamps of different candle power in the lamp holder.

The motor is started and stopped by the switch $F$. 

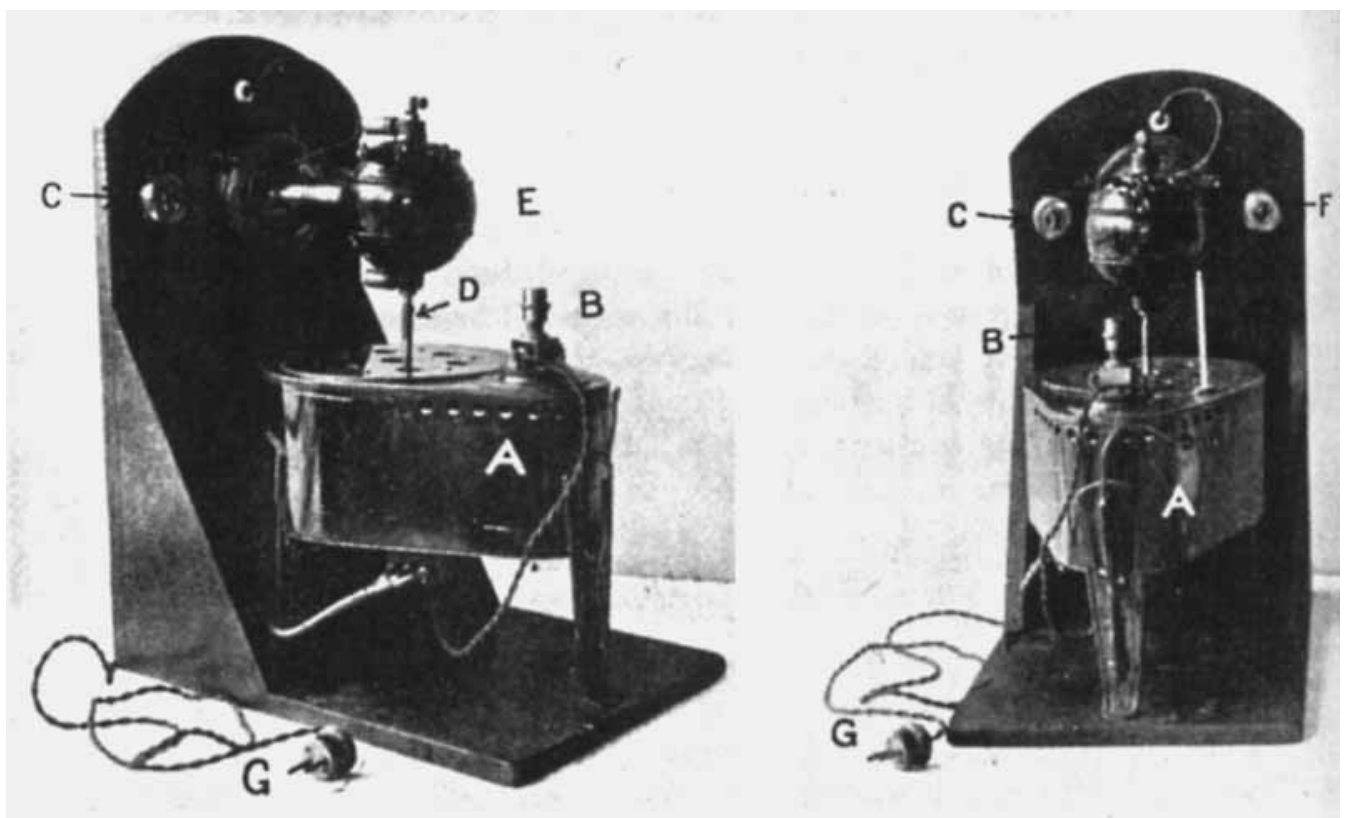

Fig. 1

Fig. 2

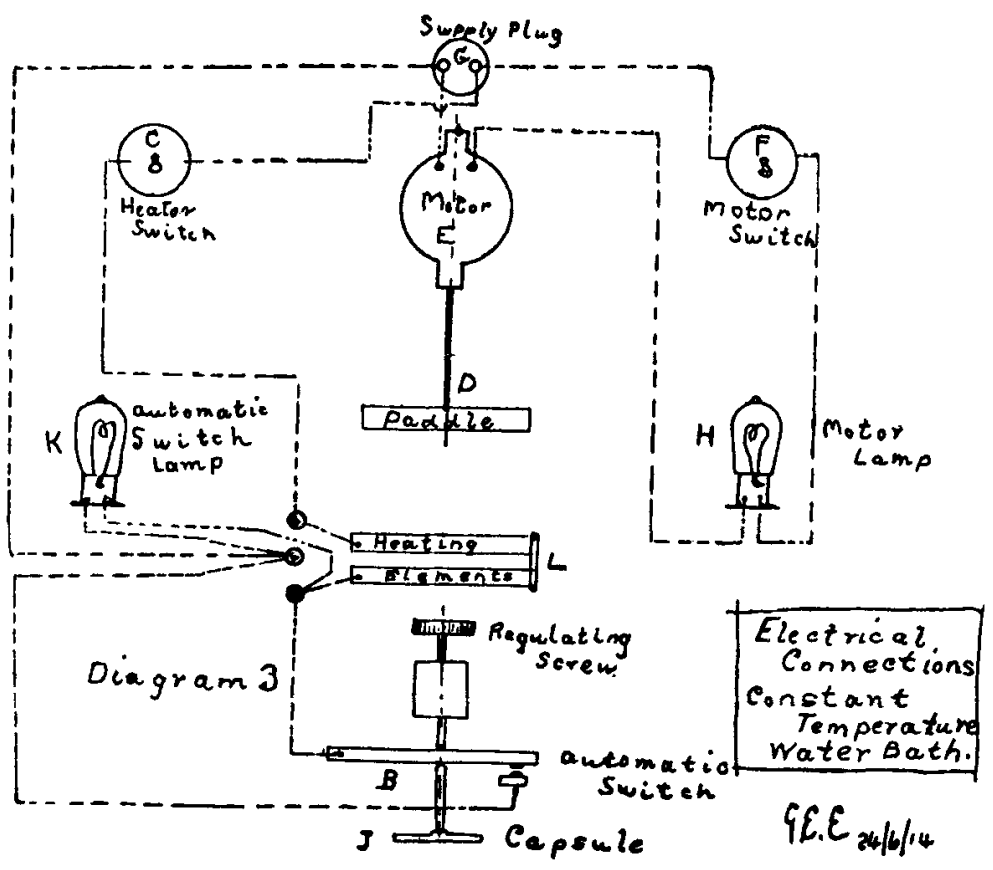

Fig. 3 
The apparatus is connected to the nearest supply plug or lamp holder by means of a flexible cord and plug or adapter.

The tests were made with specially uniform tubes of thin glass, about $18 \mathrm{~cm}$. in diameter and containing exactly $10 \mathrm{cc}$. of nutrient broth. Into each of these was introduced a loopful of a 24-hours old culture in nutrient broth, and they were placed in the water bath for ten minutes; at the end of the ten minutes the tubes were plunged into cold water to reduce the temperature and were finally placed in the incubator at $30^{\circ} \mathrm{C}$. with a number of control tubes. The thermal death point was found to be $60^{\circ} \mathrm{C}$. when determined by this method.

A second series of experiments was undertaken in order to determine the death point of the organism in a dry condition.

A number of sterile cover slips were smeared with a suspension of an agar streak in a normal saline solution. These were dried in a sterile petri dish and then exposed for ten minutes to the heat of a drying oven. At the end of this time they were taken from the petri dish with a pair of sterile forceps and dropped into tubes of nutrient broth. The broth clouded when inoculated with cover slips exposed to temperatures of $120^{\circ} \mathrm{C}$. and under, but remained clear if the cover slips dropped into it had been exposed to a temperature of $125^{\circ} \mathrm{C}$. or over. The thermal death point of the organism in a dry condition, therefore, lies between $120^{\circ} \mathrm{C}$. and $125^{\circ} \mathrm{C}$.

The organism can grow through a wide range of temperature if it is provided with sufficient moisture. It grows very slowly at $5-6^{\circ} \mathrm{C}$. and also at $45^{\circ}$. At the latter temperature nutrient broth was feebly clouded at the end of 48 hours. The optimum temperature is about $30^{\circ} \mathrm{C}$.

\section{Desiccation.}

The organism will not grow without a fair amount of moisture, and its growth is most vigorous on a wet medium and in a saturated atmosphere; on the other hand, it is very resistant to desiccation and remains alive for a long time in a dry condition.

A number of diseased leaves were dried in the air in the laboratory, being merely protected from dust. They were received on the 9th of June, 1913, and from that date cultures were made from them at intervals of a month. On the 9th of June, 1914, after the leaves had been drying for one year a vigorous culture was obtained; it has not yet been ascertained how much longer the organism retains its vitality on dried leaves. 
An experiment was also conducted to test the ability of the bacillus to withstand desiccation on glass cover slips.

A 48-hours old culture on nutrient agar was suspended in a normal saline solution and a number of sterile cover slips smeared with the suspension were put in a sterile petri dish to dry.

A Hempel desiccator containing sulphuric acid was prepared, the dry cover slips transferred to a sterile ventilated capsule, and placed in the desiccator. The latter was then sealed up and partially exhausted. At intervals cover slips were removed from this apparatus with sterile forceps and dropped into tubes of nutrient broth. After 40 days drying a culture of the organism could be still obtained from the cover slips; at the end of that time the experiment was discontinued.

\section{Resumé of Salient Characters.}

Bacillus mangiferae n.sp. An organism causing a disease of the leaves and fruit of the mango (Mangifera indica); it attacks the parenchyma, causing black angular spots on the leaves; and on the fruit discoloured roughened areas often accompanied by deep longitudinal cracks.

A short motile rod with rounded ends averaging $1.5 \times \cdot 6 \mu$; usually single, chains formed in pellicle on liquid media; motile, with $2-8$ long, peritrichiate flagella; no spores observed; capsules in ring above liquid media; involution forms (?) in broth containing high percentages of $\mathrm{NaCl}$; stains readily with usual stains and by Grane's method.

Forms shining yellowish colonies on nutrient agar, undulate at $25^{\circ} \mathrm{C}$.; liquefies gelatine; clouds nutrient broth forming ring pellicle and sediment; grows readily on blood serum, but does not cause liquefaction; grows slowly in milk finally causing coagulation, at $37^{\circ} \mathrm{C}$. the casein is slowly dissolved. Grows on potato making a shining yellowish spreading growth over moist part of medium; the latter is not discoloured; heavy growth on beet and in beet juice, also in cabbage broth; slightly clouds Cohn's solution; no growth in Uschinsky's solution or on starch jelly made with Fermi's solution.

No gas formation in carbohydrate media, but medium becomes slightly more acid. No formation of diastatic or invertin enzymes, small percentage of alcohol in dextrose broth; nitrates reduced, tolerates up to $8.75 \% \mathrm{NaCl}$; reduces litmus and several other colouring matters; indol in media containing peptone but no phenol.

Aerobic, facultative anaerobe; very sensitive to action of mercuric 
chloride, but less so to copper sulphate; not sensitive to sunlight; will not grow without moisture, but is not easily killed by desiccation; will grow in media of widely different reaction, optimum reaction about +17 Fuller; maximum temperature for growth $45^{\circ} \mathrm{C}$., thermal death point $60^{\circ} \mathrm{C}$. Group No. 221. 2223532 .

\section{Summary.}

1. A disease of mangoes, hitherto undescribed, has for the last few years been causing considerable loss to mango growers in the Union.

2. So far as can be ascertained the disease is not known outside South Africa, and it occurs in this country in the neighbourhood of Barberton and Warmbaths, in the coast region of Natal and at Delagoa Bay.

3. Dark angular spots are formed on the leaves which do not noticeably affect the general health of the tree, but serve as a source of infection for the fruit. On the latter the disease causes discoloured roughened areas and deep cracking; infected fruit is detached from the tree by the slightest air movement and falls rotting to the ground.

4. Infection is carried by the wind, and by rain dripping from infected leaves. Very few insects are found on the mango foliage.

5. Spraying experiments have been conducted which show that spraying with Bordeaux mixture, iron sulphide or Hycol is useless in checking the disease.

6. The cause of the trouble is a flagellate bacillus Bacillus mangiferae n. sp. It invades the parenchyma, wedging apart and killing the cells and causing gummosis; lignified tissues are not touched.

7. The organism is described in detail and a resumé is given of its salient characters.

\section{AckNowledgment.}

I wish to acknowledge my indebtedness to Mr I. B. Pole Evans, Chief Division of Botany, in whose laboratory the work was done, for many helpful suggestions; and to Mr E. E. Ensor of the Public Works Department for adapting the apparatus described in connection with the thermal death point determinations.

The names of the varieties of mangoes grown in this country were furnished by M. D. d'Emmerez de Charmoy, of the Department of Agriculture, Mauritius. 
I have also to thank Messrs Winter Brothers, of Barberton, who placed their orchard at our disposal for the spraying experiments, and who have repeatedly supplied us with mango fruit for experimental purposes.

\section{BIBLIOGRAPHY.}

1. Amkroian Public Healte Association : Standard Methode of Water Analysis. New York, 1912.

2. Bzisson, A. Practical Bacteriology, Microbiology and Serum Therapy. Longmans, Green and Co., 1913.

3. Cardur, P. P. Bloom Blight of Mango in Cuba. Cuba Review, Vol. vili. (1910), No. 5, pp. 28, 29.

4. Chester, F. D. A Manual of Determinative Bacteriology. The Macmillan Co., 1901.

5. Colusns, G. N. The Mango in Porto Rico. United States Department of Agriculture, Bureau of Plant Industry, Bulletin 28, 1903.

6. Cook, MrLville T. The Diseases of Tropical Plants. Macmillan and Co., London, 1913.

7. Eusus, D. On the digcovery of Cilia in the genus Bacterium. Centralblatt $f$. Bakt. II Abt. Bd. xI. p. 241.

8. Eyre, J. W. H. Bacteriological Technique, 2nd edition, 1913.

9. Higarss, J. E. The Mango in Hawaii. Hawaii Agric. Expt. Station, Bulletin $12,1906$.

10. Marirs, C. Indian Mangoes. Journal Royal Hort. Soc., London, xxvr. pp. 755-770, 1901-02.

11. Popinoe, F. W. The Mango in South California. Pomona College, Journ. Economic Bot. I. No. 4, Dec. 1911.

12. RIDGWAY, ROBRRT. Color Standards and Nomenclature. Waehington, D.C., 1912.

13. Smith ERwin, F. Bacteria in relation to Plant Diseases, Vol. I. Carnegie Institute of Washington, 1905.

14. Woodrow, G. M. The Mango, its Culture and Varieties. Paisley, 1904.

15. ? The Mango, Trinidad Bulletin, July, 1899, No. 20.

\section{EXPLANATION OF PLATES.}

All drawings were made with the aid of the camera lucida, except figures $c-h$ of Plate XI, which were drawn freehand as explained in the text.

Plate I. Three colour photograph of small branch bearing diseased fruit. (Reproduced, from nature, by the Government Printer, Pretoria.)

Plate II. Mango leaves showing the dark coloured, angular spots, characteristic of the diserse.

Plate III. Small branches which have been infected through hail injuries. A small portion of bark has been removed from the left-hand branch to show the discolouration of the underlying tissues.

Plate IV. Half-grown fruit showing disooloured roughened areas caused by Bacillus mangiferae. 


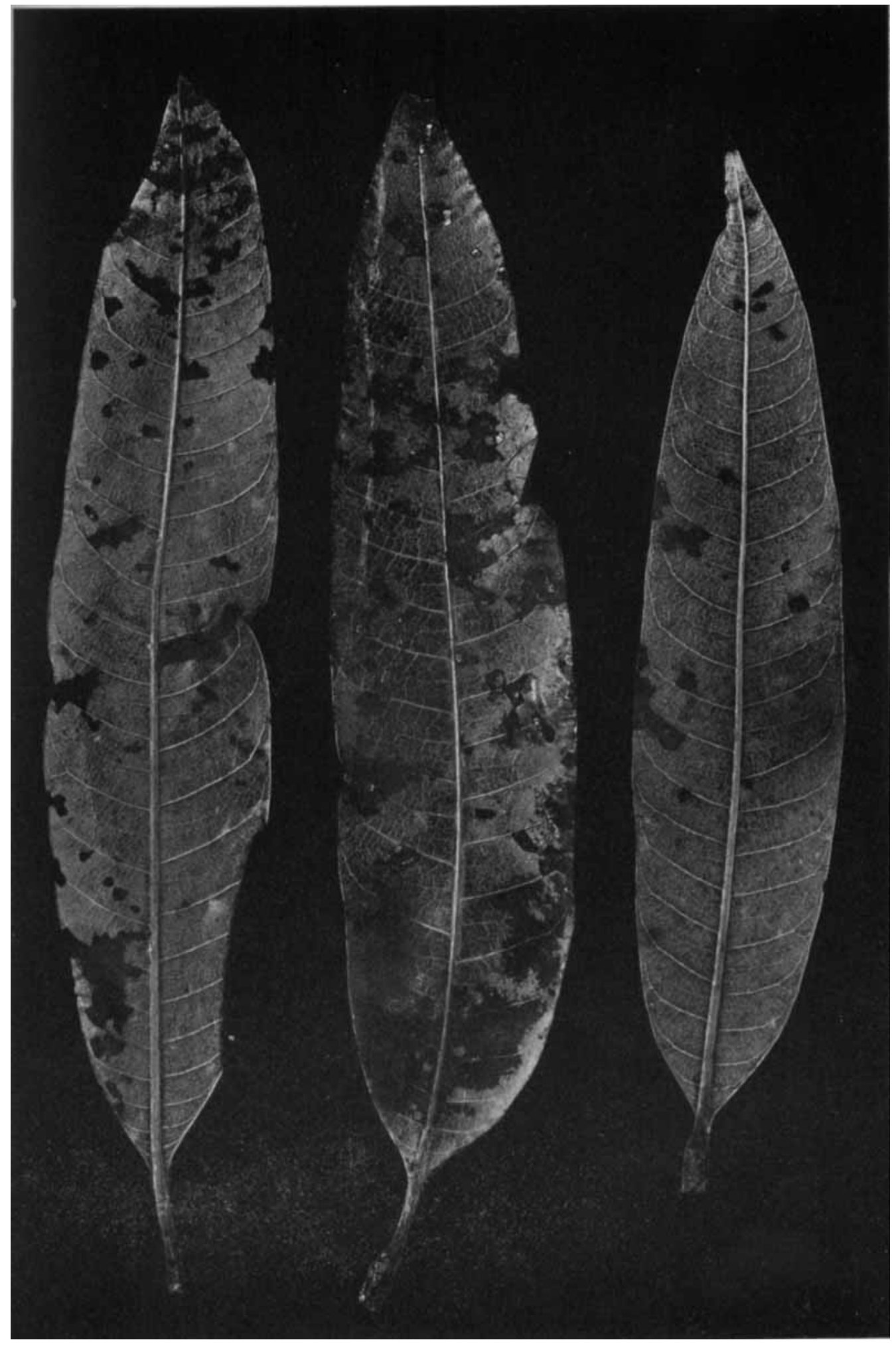


THE ANNALS OF APPLIED BIOLOGY. VOL. II, NO. 1

PLATE III

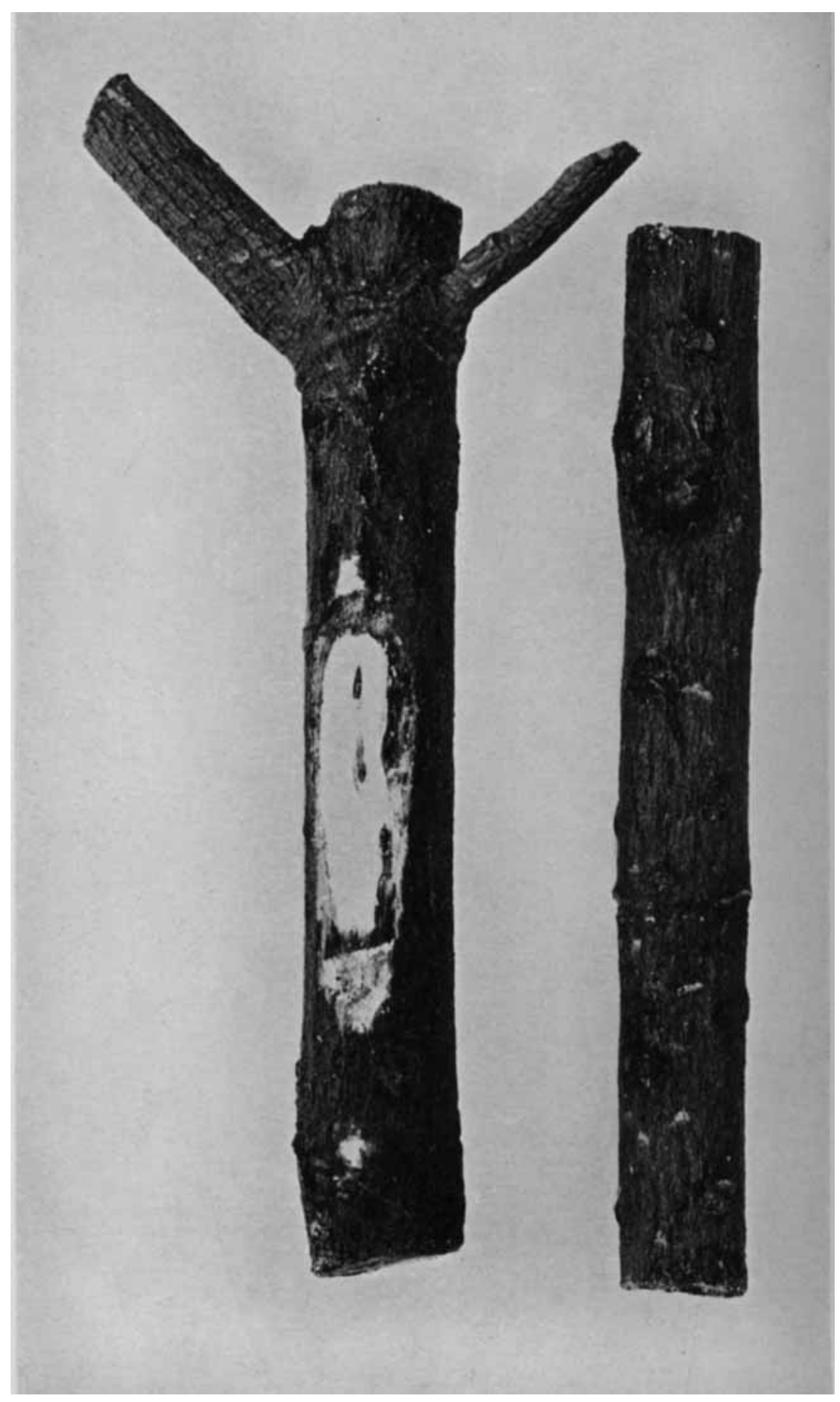


THE ANNALS OF APPLIED BIOLOGY, VOL. II, NO. 1

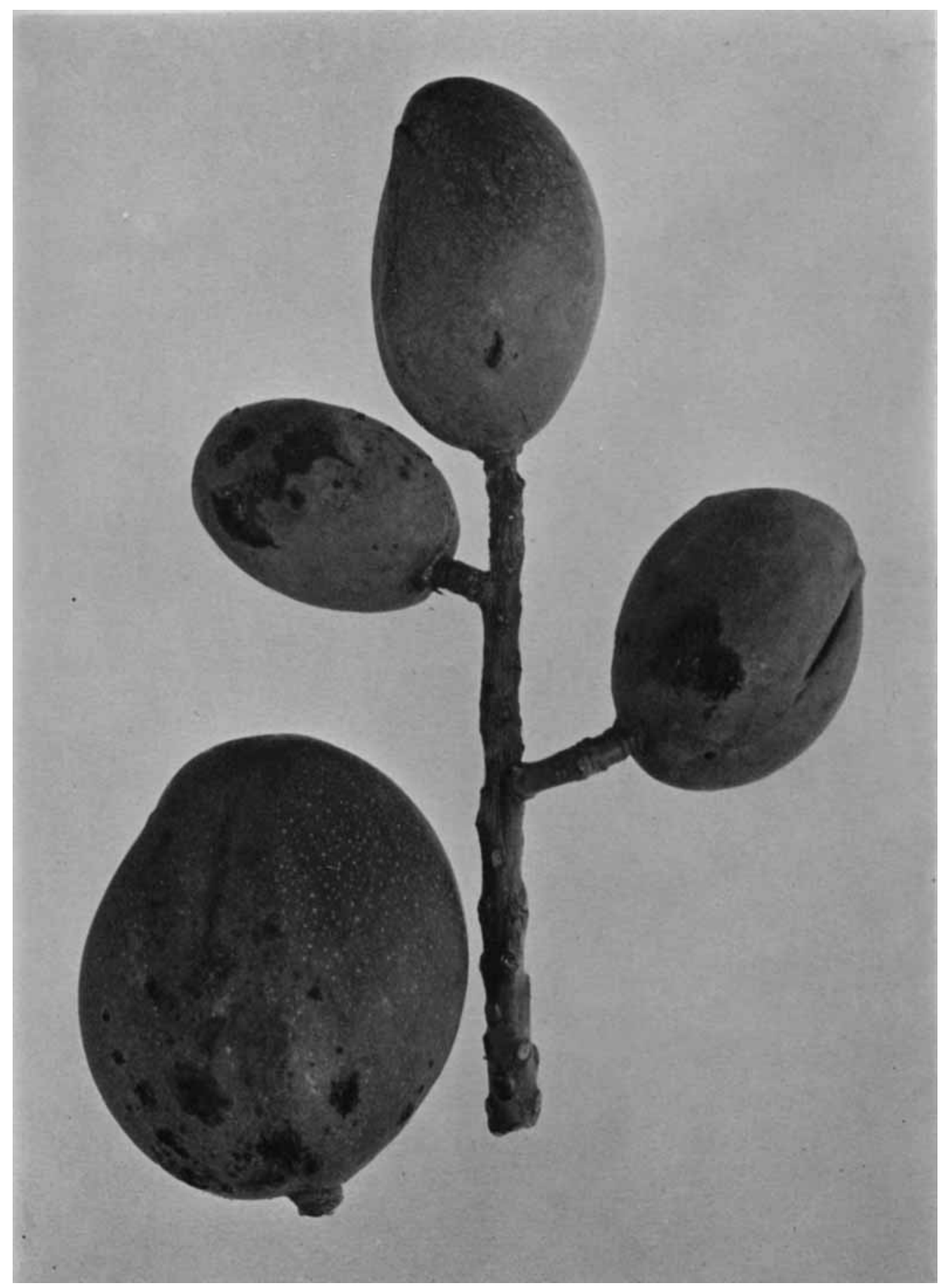




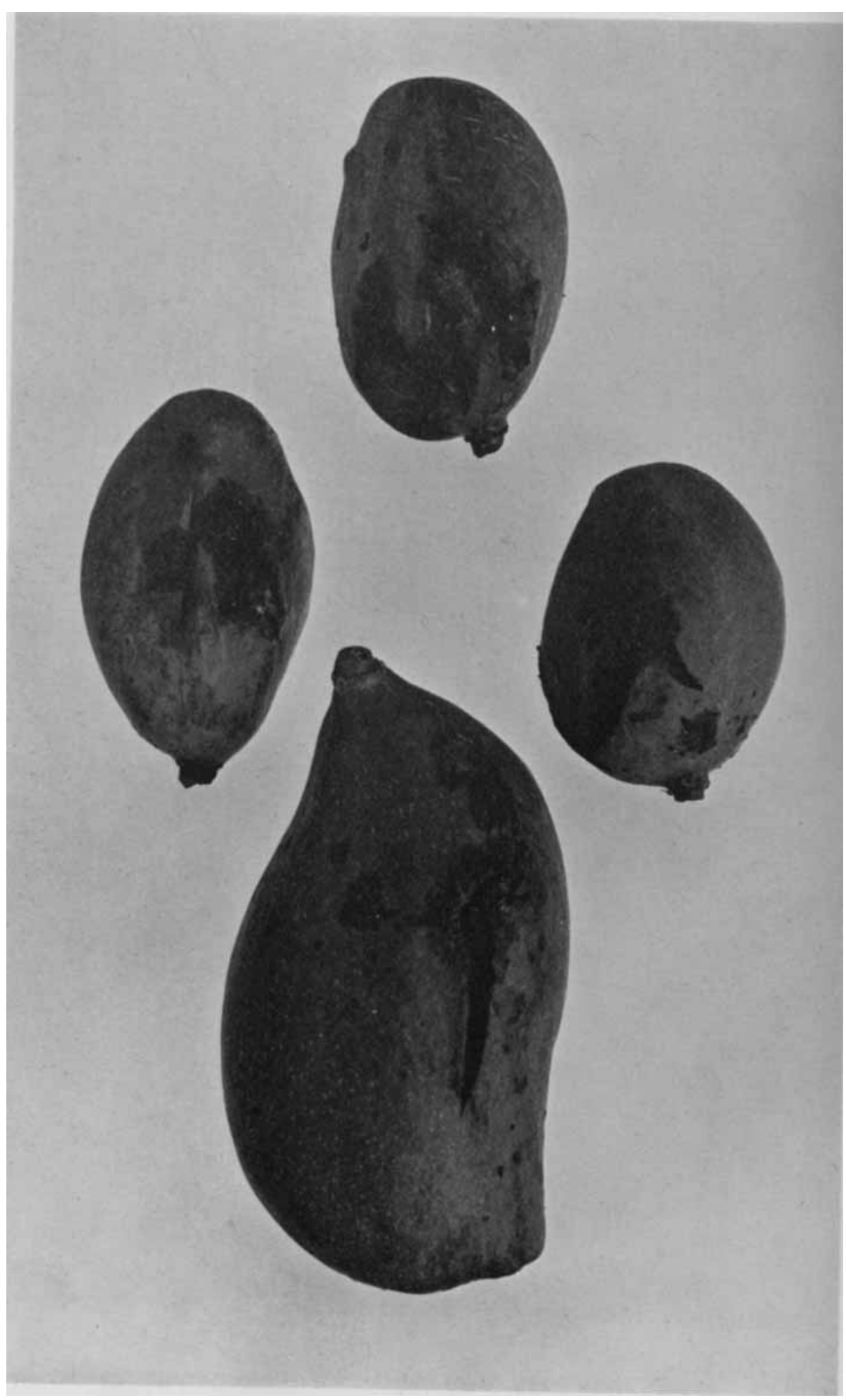




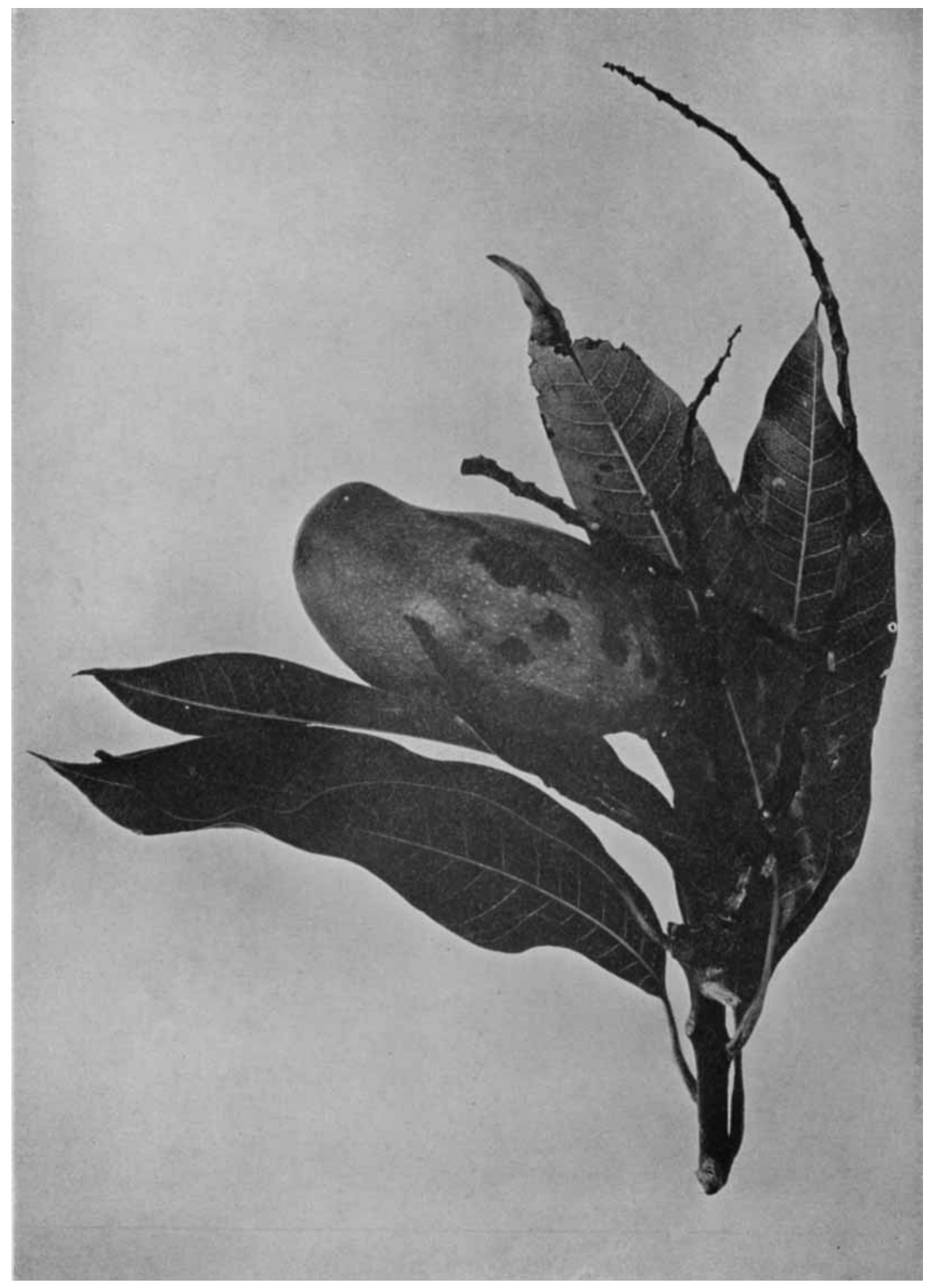


THE ANNALS OF APFLIED BIOLOGY, VOL. II, NO. 1

PLATE VII

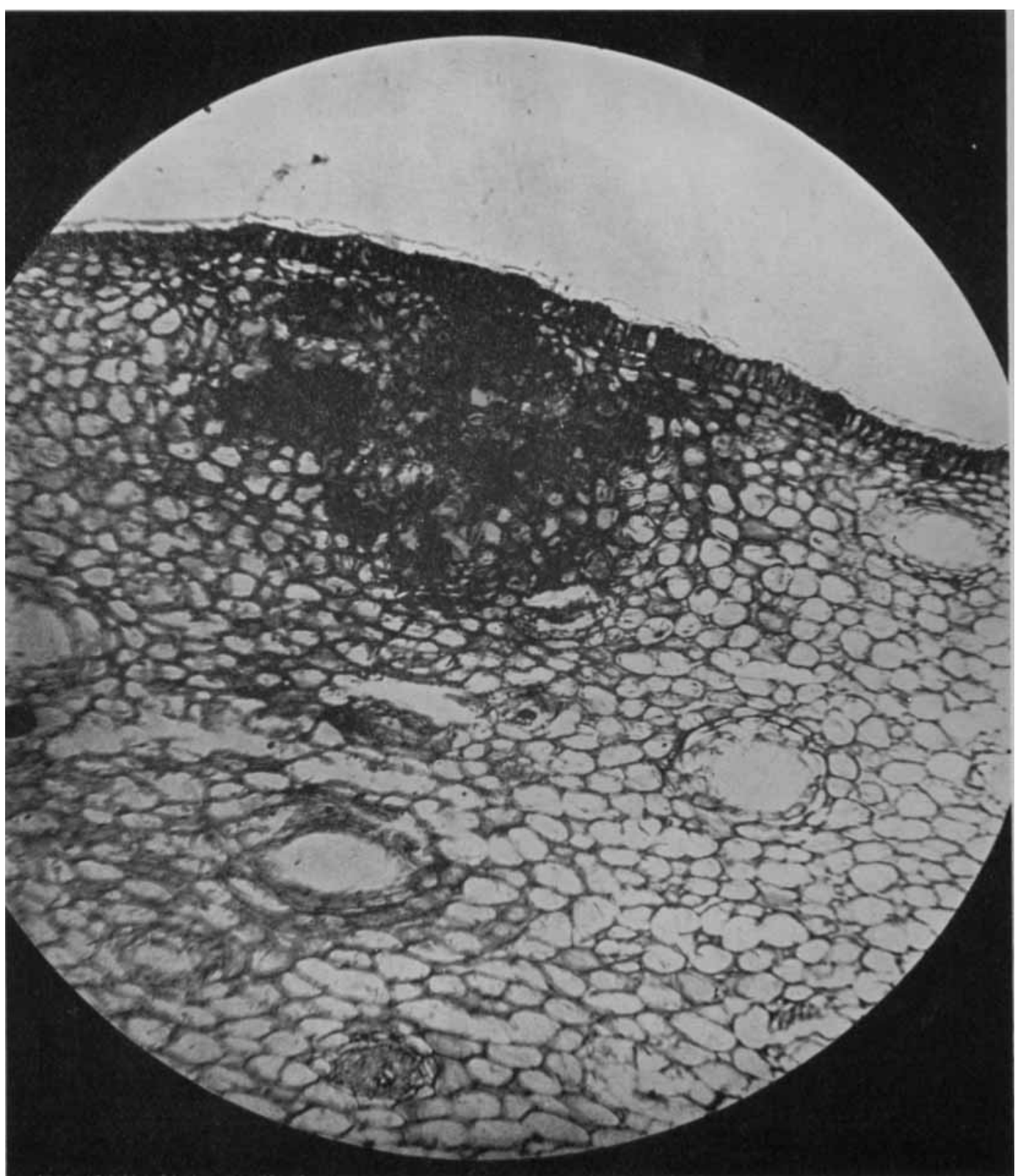




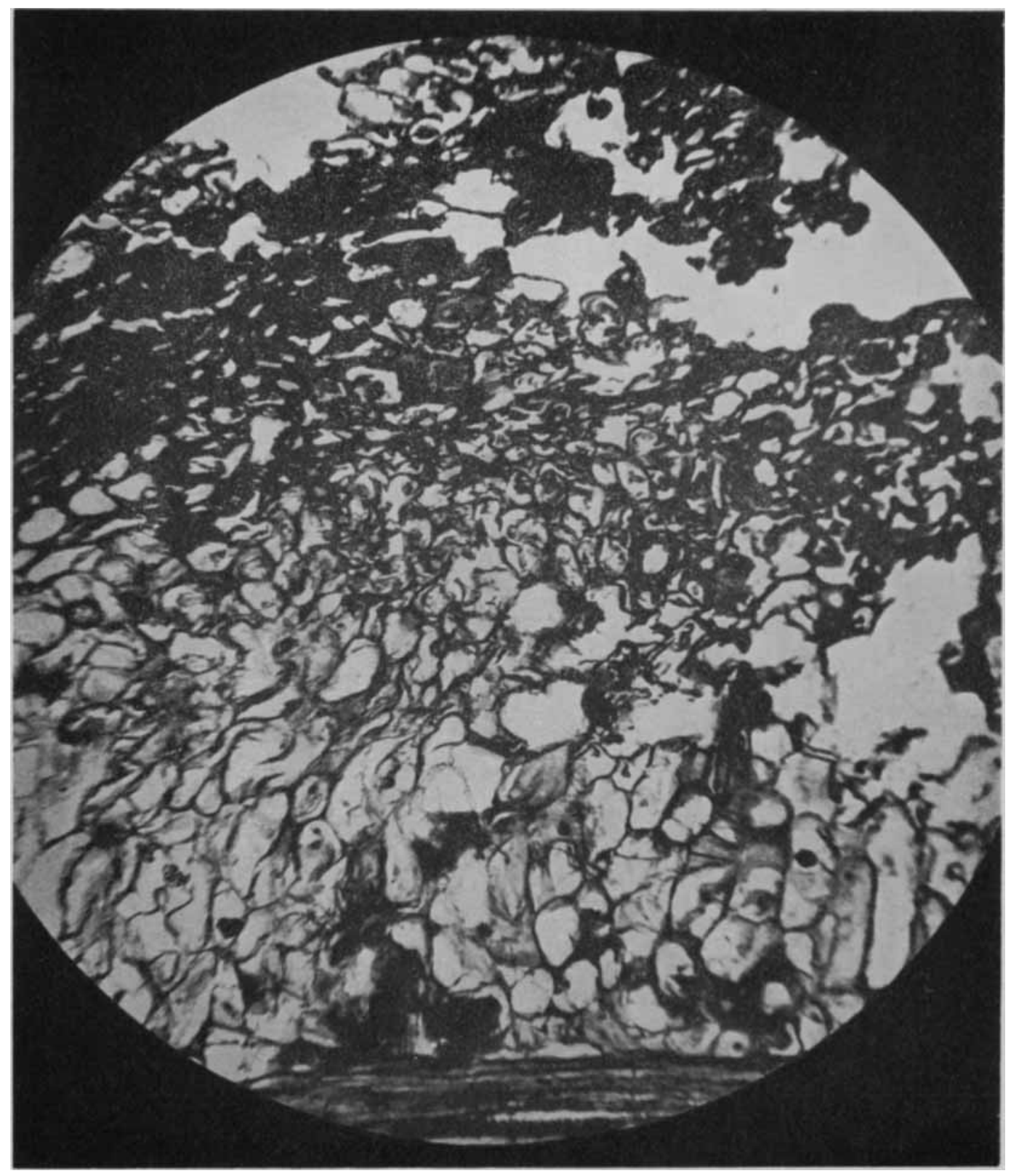




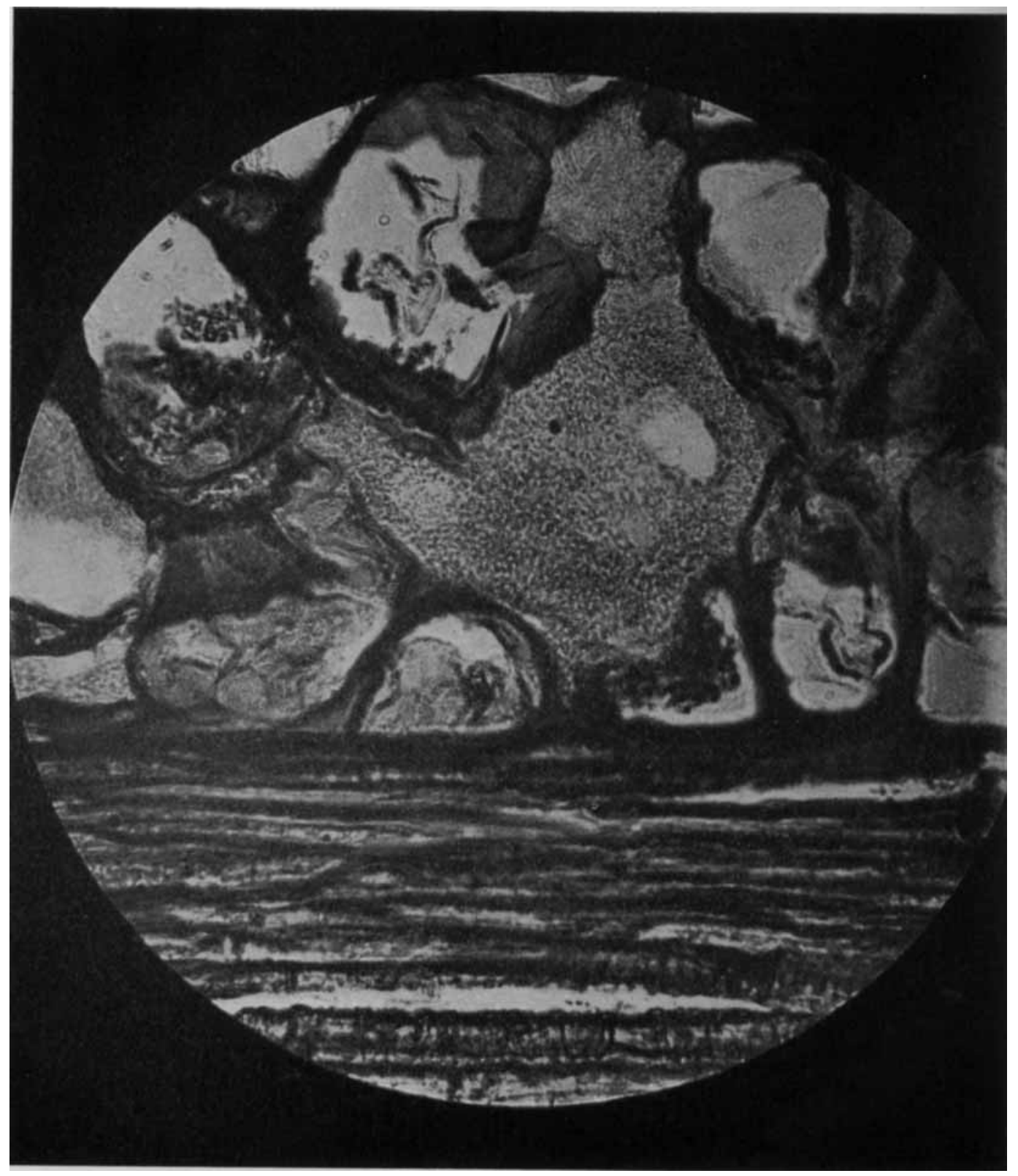


THE ANNALS OF APPLIED BIOLOGY, VOL. II, NO. 1

PLATE $X$

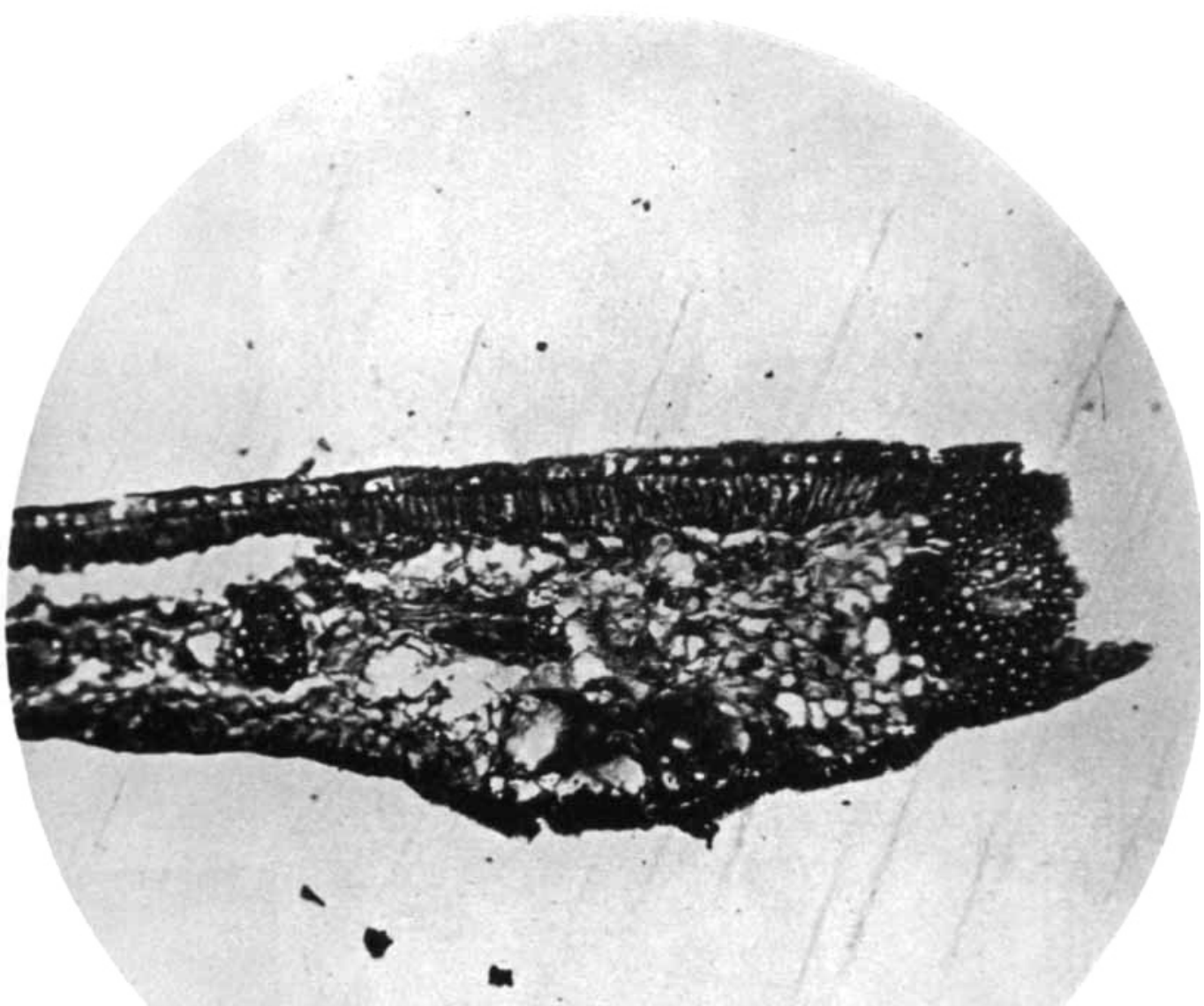


THE ANNALS OF APPLIED BIOLOGY. VOL. II, NO. 1

PLATE XI
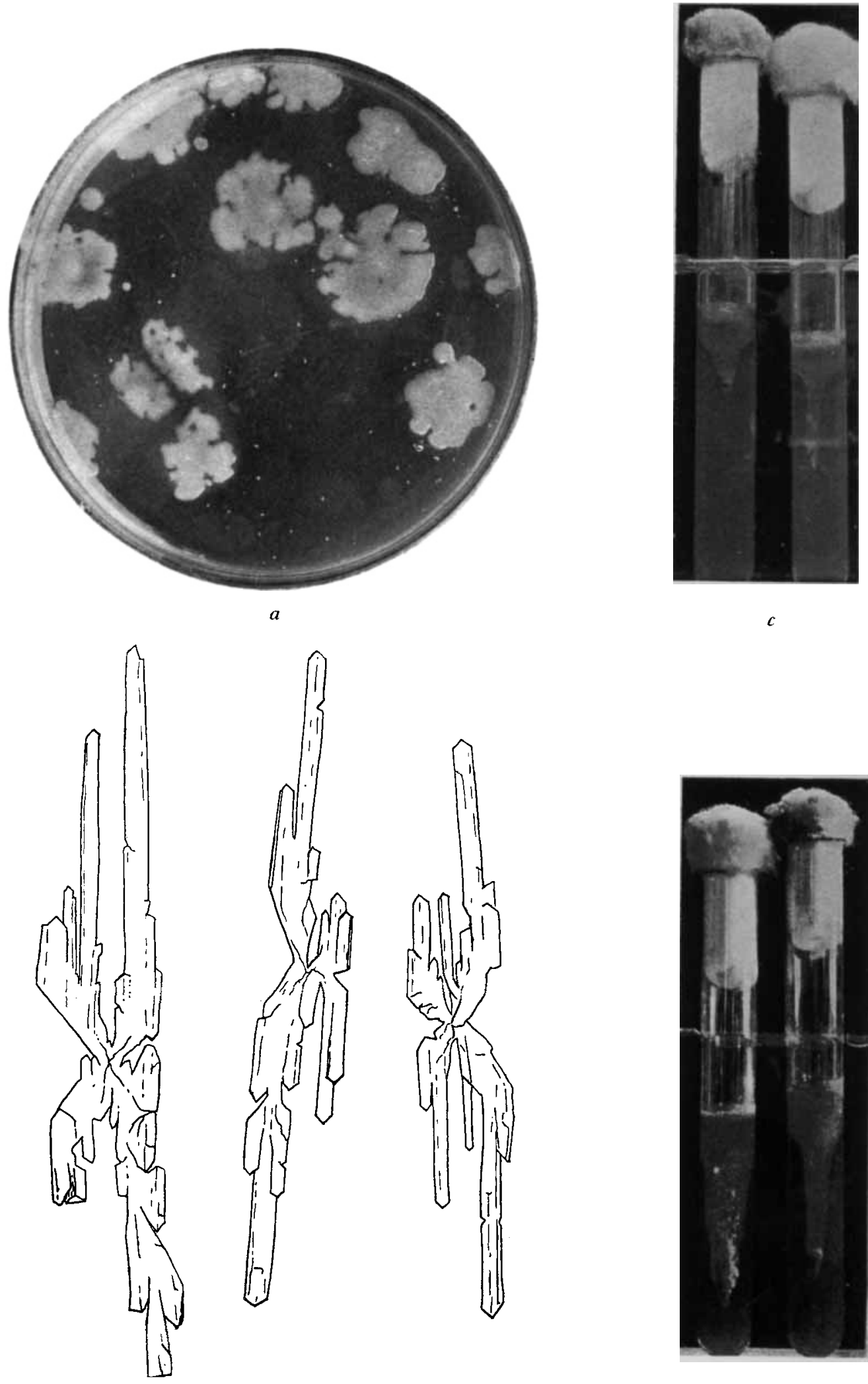


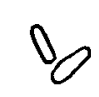

$a$
11.15 a.m.

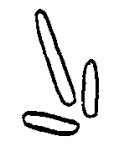

$f$
1.55 p.m.

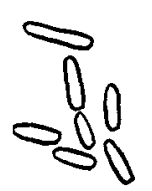

$j$

2.32 p.m.

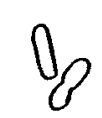

$b$
12.55 p.m.

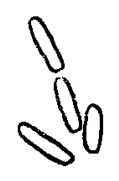

$2.10^{g}$ p.m.

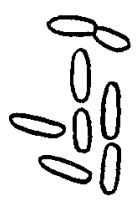

$k$
2.45 p.m.

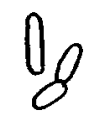

$c$
$1.10^{\circ}$ p.m.

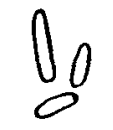

$d$
$1.25 \mathrm{p} . \mathrm{m}$.

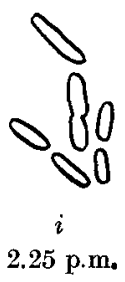

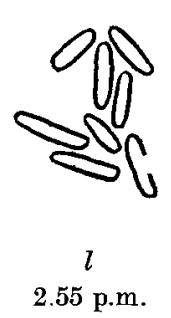
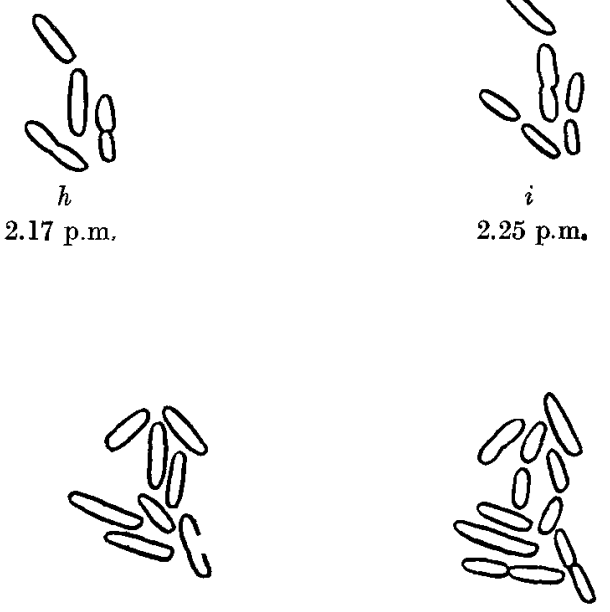

$m$ 3.10 p.m.

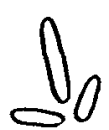

$e$
1.40 p.m.

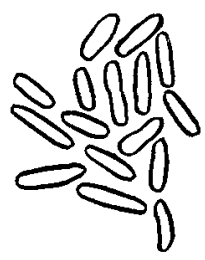

$n$
3.40 p.m.

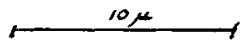

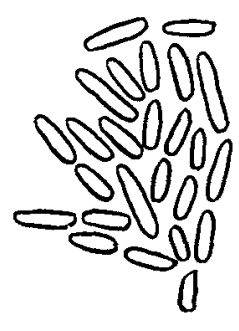

$o$
4.0 
THE ANNALS OF APPLIED BIOLOGY. VOL. II, NO. 1

PLATE XIII
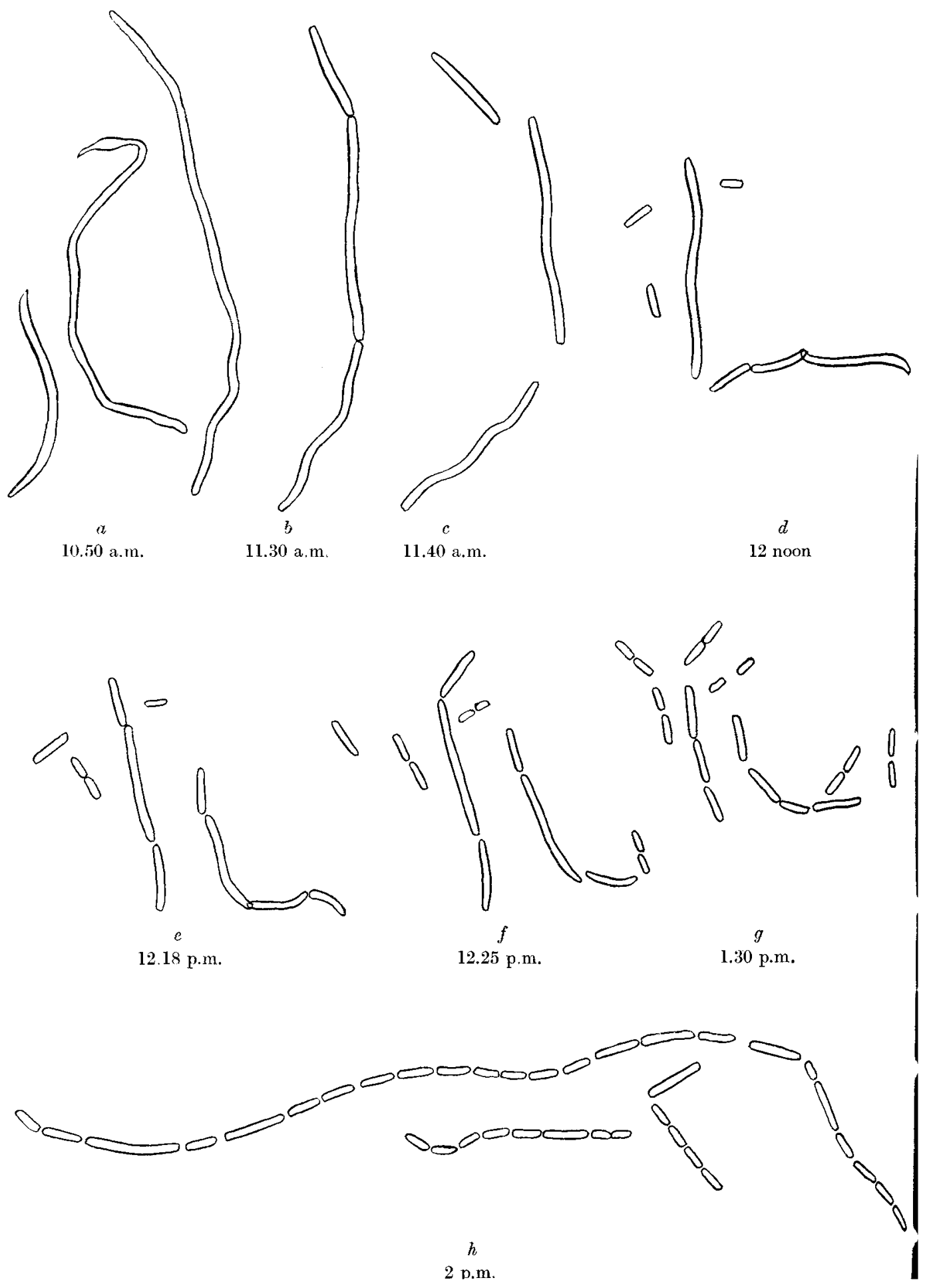

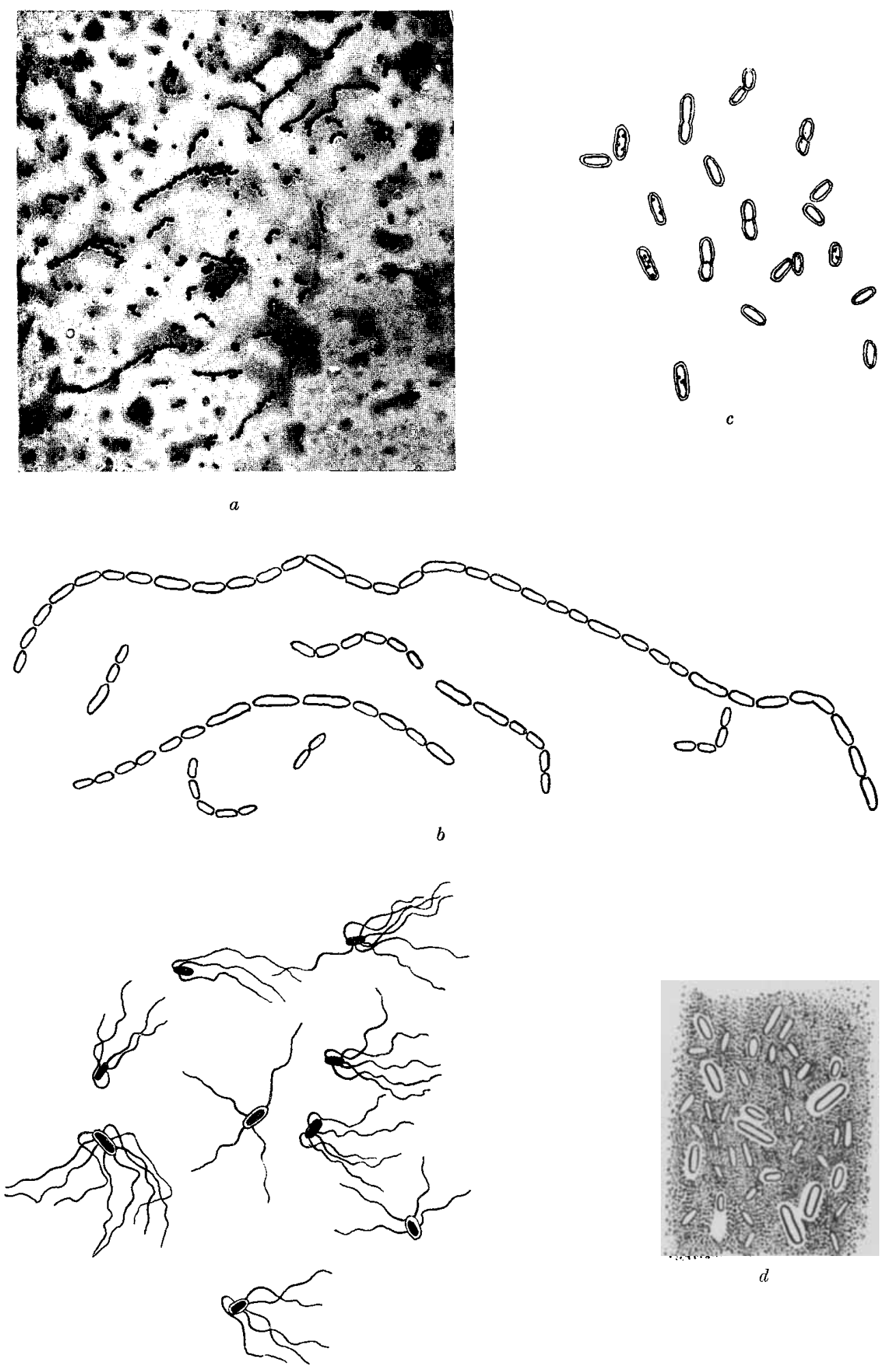
Plate V. Mangoes in a more advanced stage of the disease; deep longitudinal cracks have formed.

Plate VI. In this case the whole inflorescence has been destroyed; the one remaining fruit fell off as the photograph was taken.

Plate VII. Photomicrograph of section through fruit, showing an early stage of the disease. The dark area consists of crushed, discoloured cells, with masses of bacilli in the intercellular spaces. (Photographed with Zeiss' achromatic objective D, and compensating ocular No. 6.)

Plate VIII. Photomicrograph of section through fruit in a more advanced stage of the disesse. The superficial cells are crushed and dead; there are very fow bacilli in this region. They are very numerous in the more deeply seated tissues, a small fibro-vascular bundle at the foot of the plate is surrounded by them, but untouched. Same magnification as Plate VII.

Plate IX. Detail trom Plate VIII., in the neighbourhood of the fibro-vascular bundle. The bacilli can be clearly seen in the intercellular spaces, wedging the cells apart. (Zeiss oil imm.; obj. 2 mm., 1.4 app.; comp. ocular No. B.)

Plate $\mathbf{X}$. Photomiorograph of section through diseased spot on leaf. The increase of thickmess due to the swelling of the disorganised cells is very evident; two small vasoular bundlea in the field have not been attacked. The organism has invaded the tiasues from the underside of the leaf, the palisade cells still being intact. There are no stomata in the epidermis of the upper side of the leaf. (Same magnification as Plate VII.)

Plate XI. (a) Plate culture of Bacillus mangiferae photographed after five days at $25^{\circ} \mathrm{C}$.

(b) Crystals from plate culture in +15 nutrient agar, 10 days old. Photographed from a drawing made with camera lucida, and Zeiss achrom. obj. AA., ocular No. 1.

(c) Stab cultures in nutrient gelatine photographed after 20 days at $20^{\circ} \mathrm{C}$.

(d) The same culture seven days later.

Plate XII. a-o. Development of a small colony as observed on agar hanging block: For fuller explanation see text. (Zeiss $1 / 12$ obj. oil imm. and No. 12 compensating ocular.)

Plate XIII. $a-h$. Stages in the segmentation of long threads developed in nutrient broth containing $8.5 \mathrm{NaCl}$. Full explanation in tert.

Plate XIV. (a) Photomicrograph of chains formed in pellicle on nutrient broth, eight days at $30^{\circ} \mathrm{C}$., stained with MacConkey's capsule stain.

(b) From same preparation as above, drawn with camera lucida, Zeiss oil imm. obj. 1/12 and compensating ocular No. 12.

(c) Bacilli from $2 \%$ dextrose broth, three days at $30^{\circ} \mathrm{C}$. (Paraboloid condenser, Zeiss apochrom. obj. $3 \mathrm{~mm}$., apert. 0.95 , compensating ocular No. 18.)

(d) Capsuled rods from ring above nutrient broth, 15 days at $30^{\circ} \mathrm{C}$., MacConkr $y^{\prime} \mathrm{s}$ capsule stain. Zeiss oil imm. obj. 1/12, comp. ocular No. 12.

(e) Bacillus mangiferae with fiagella, from culture on nutrient agar, 20 hours at $25^{\circ} \mathrm{C}$. Stained by Ellis' modification of Loeffler's method. Same magnification as (d).

[Note by Editor. It has been necessary to reduce the size of some of the figures; for hich allowance must be made in the estimate of magnification.

Plates VII, VIII, IX and X have each been reduced by one-eighth.

On Plate XI, figs. $c$ and $d$ have been reduced by one-eighth.

Plate XIII, all figures reduced by one-sixth.

Plate XIV, figs. $c$ and $e$ reduced by one-fifth.]

Botanical Laboratories of the Union of South Africa, Pretoria. 